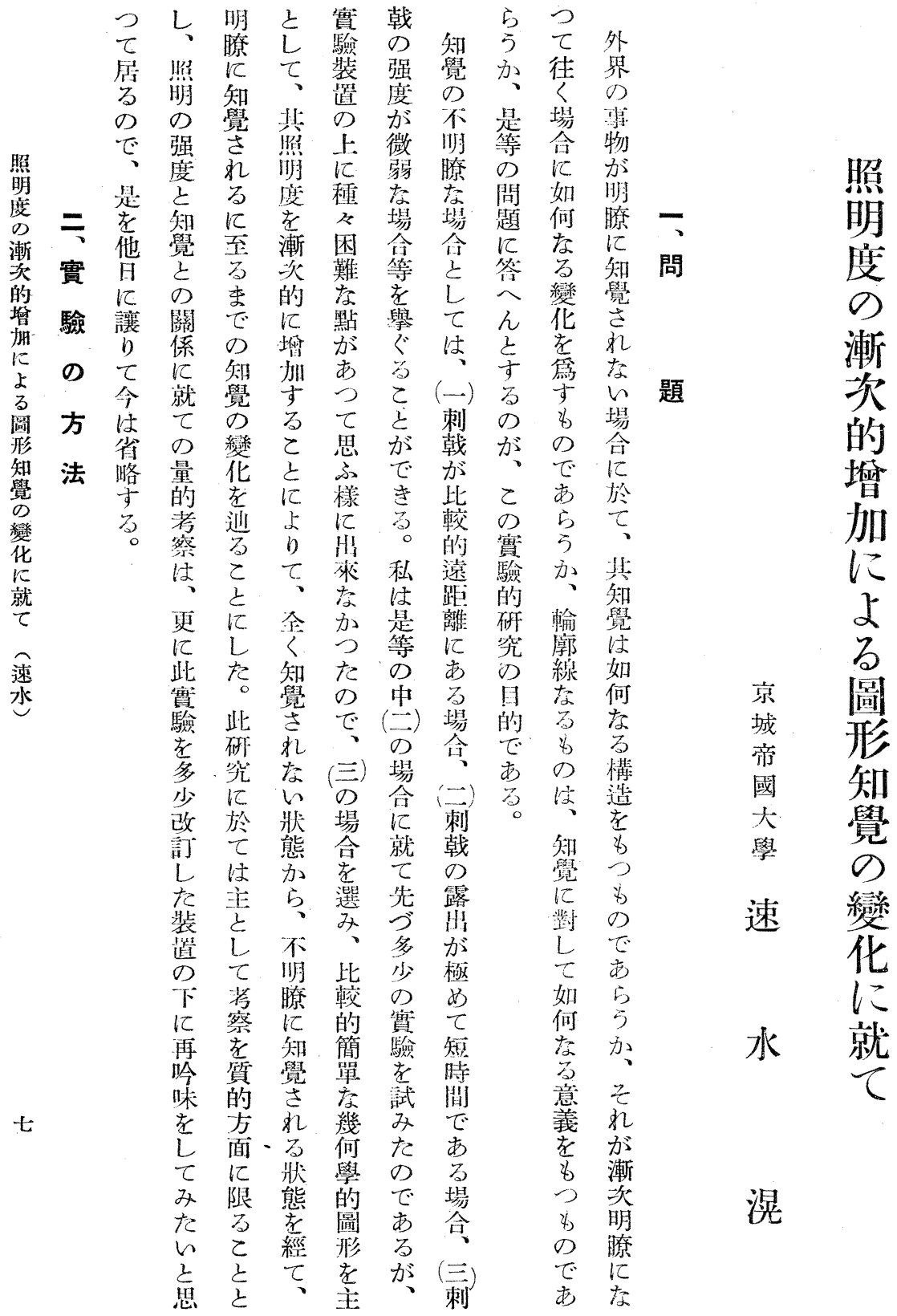




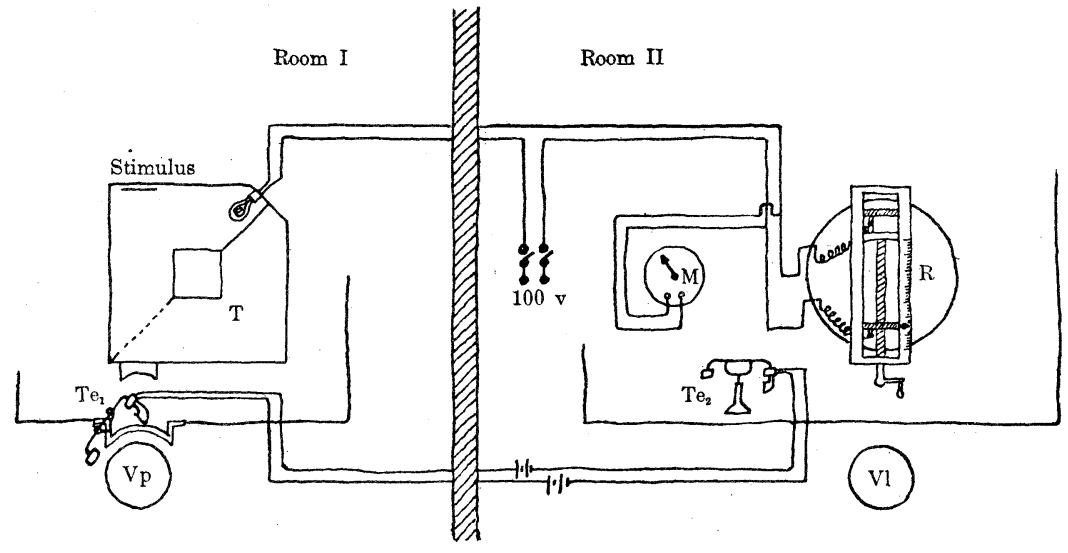

\begin{tabular}{c} 
心 \\
理 \\
學 \\
研 \\
究 \\
第 \\
卷 \\
第 \\
哲 \\
輯 \\
\hline
\end{tabular}

T...Dodge's Tachistoscope

Fig. 1

M. . . Volt Meter

$$
\begin{aligned}
& \text { R...W Water Rhecstat } \\
& \text { Te..Telephon }
\end{aligned}
$$

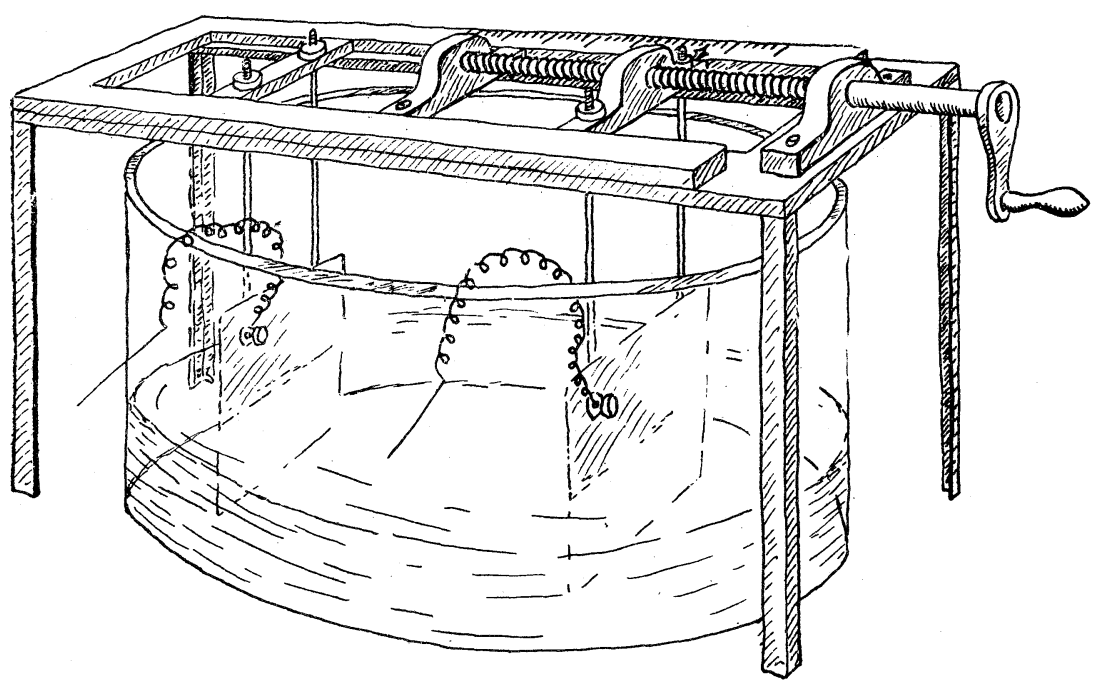

Fig. 2

Water Rheostat 


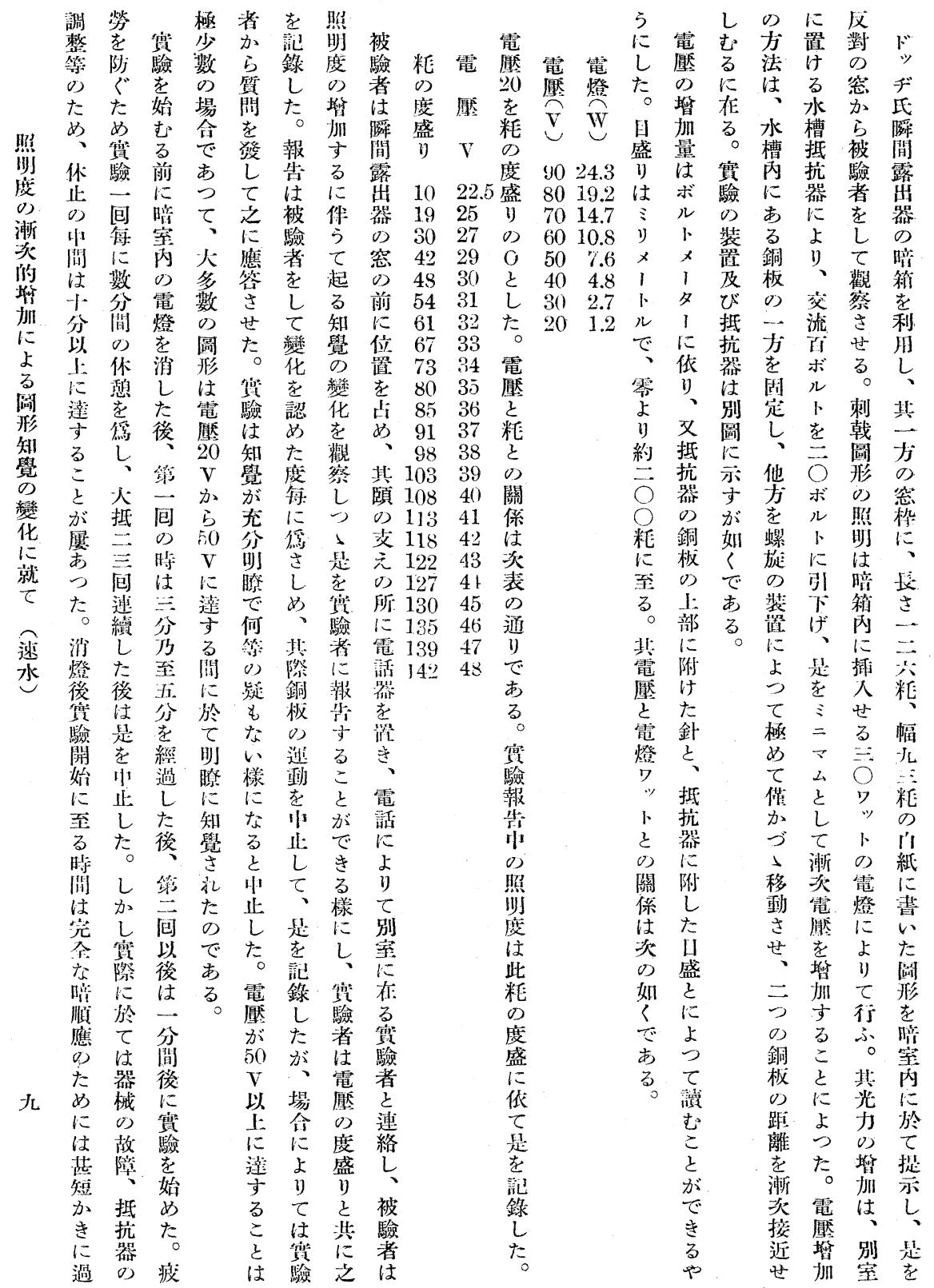




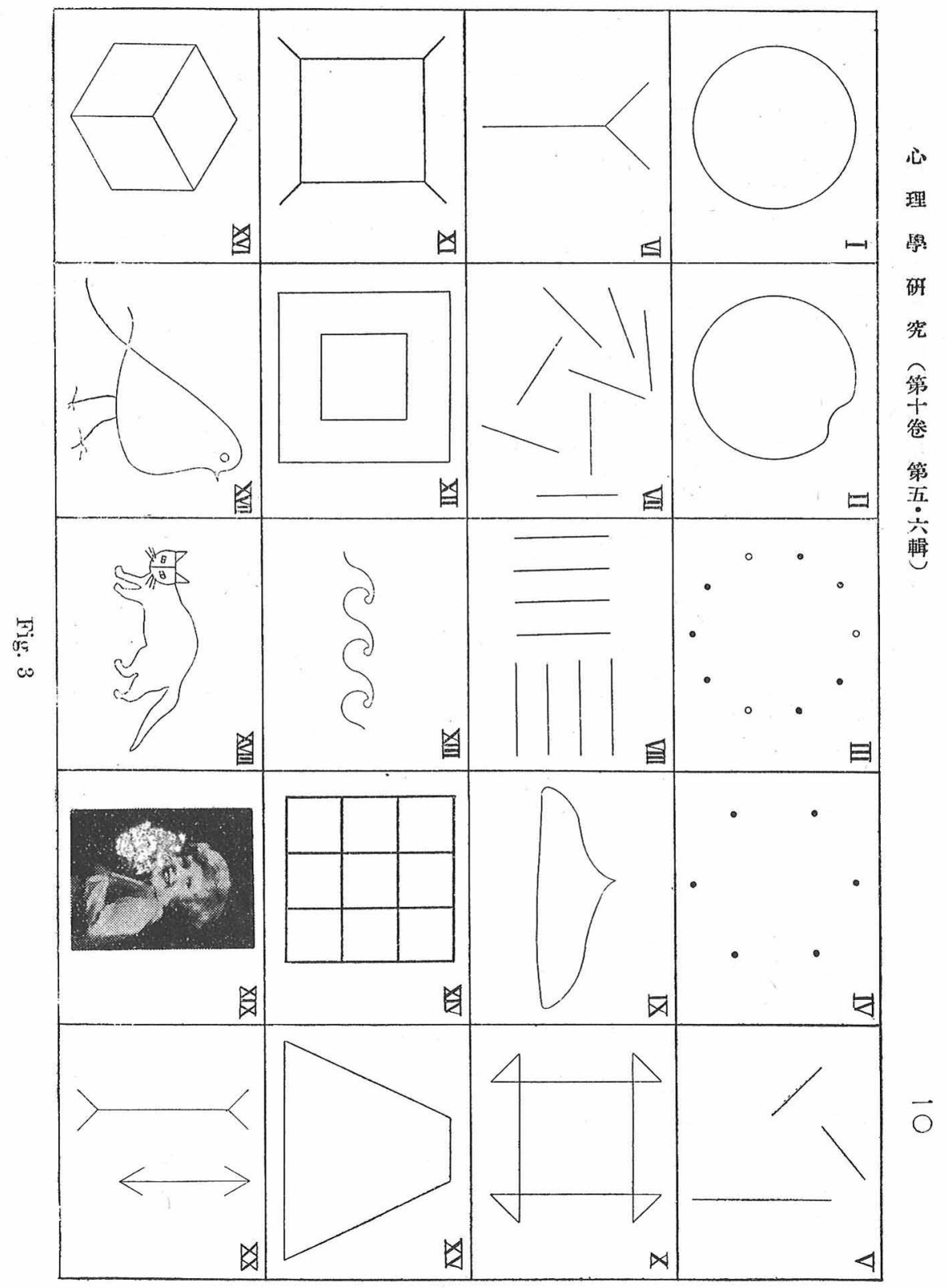




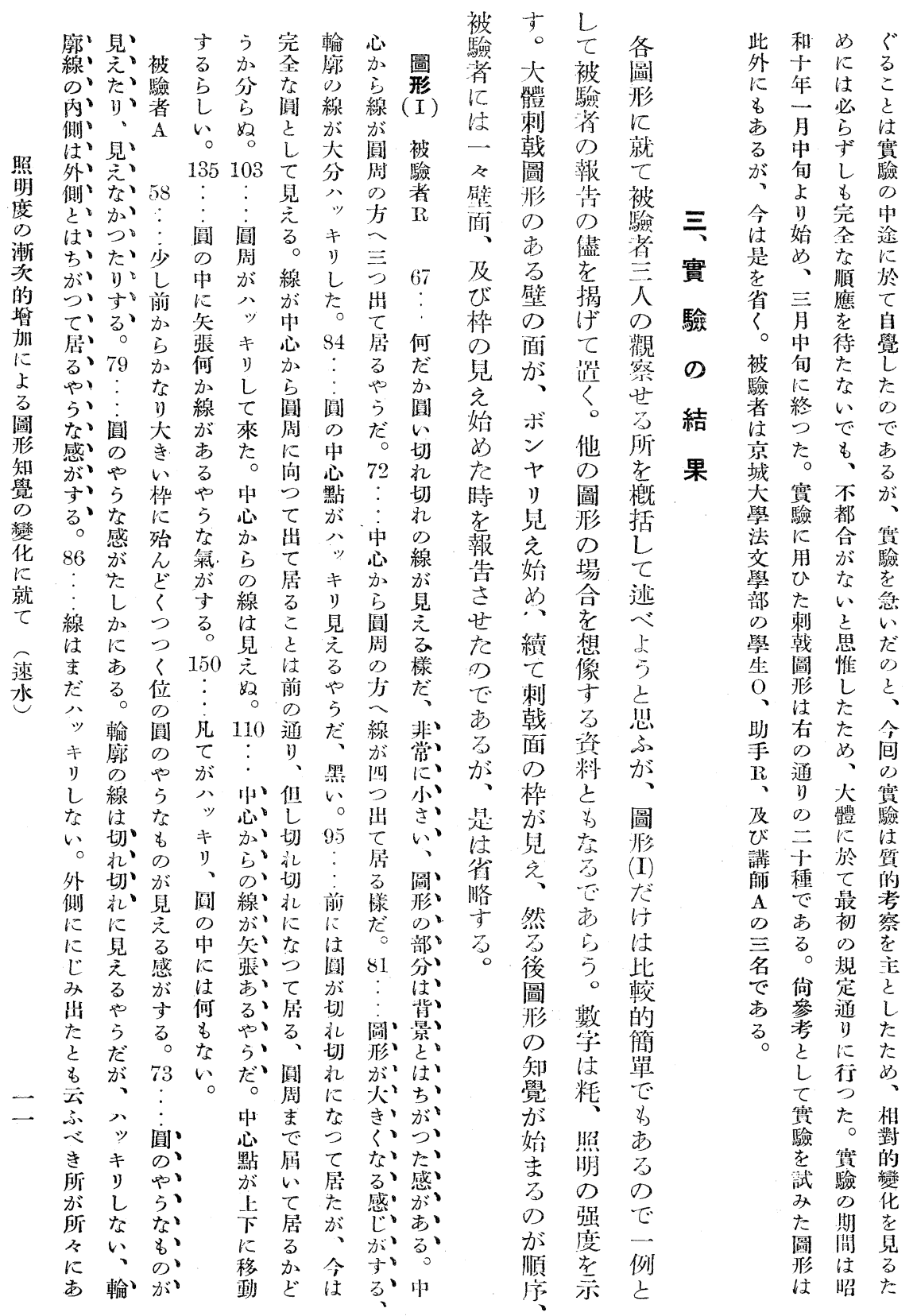




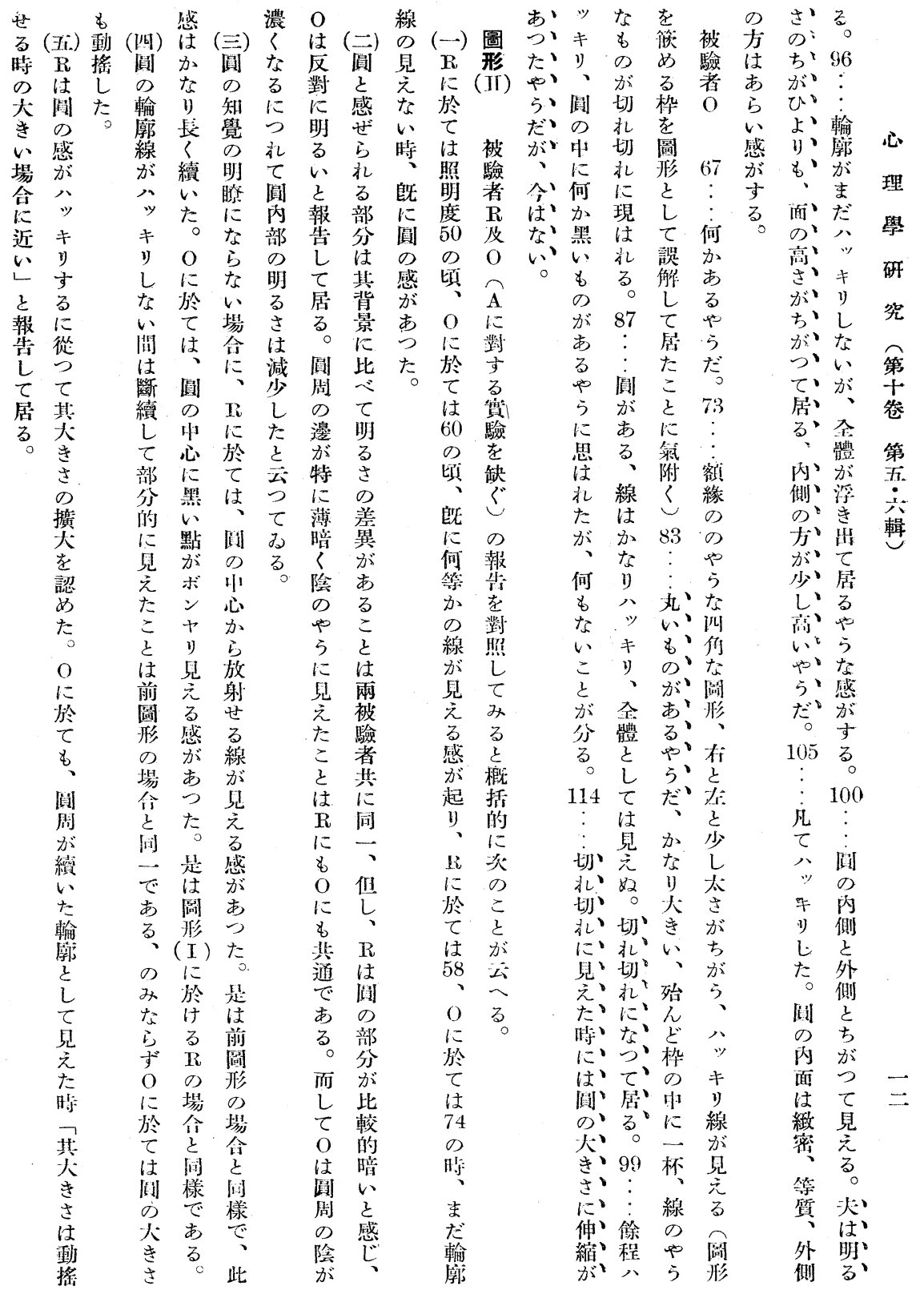




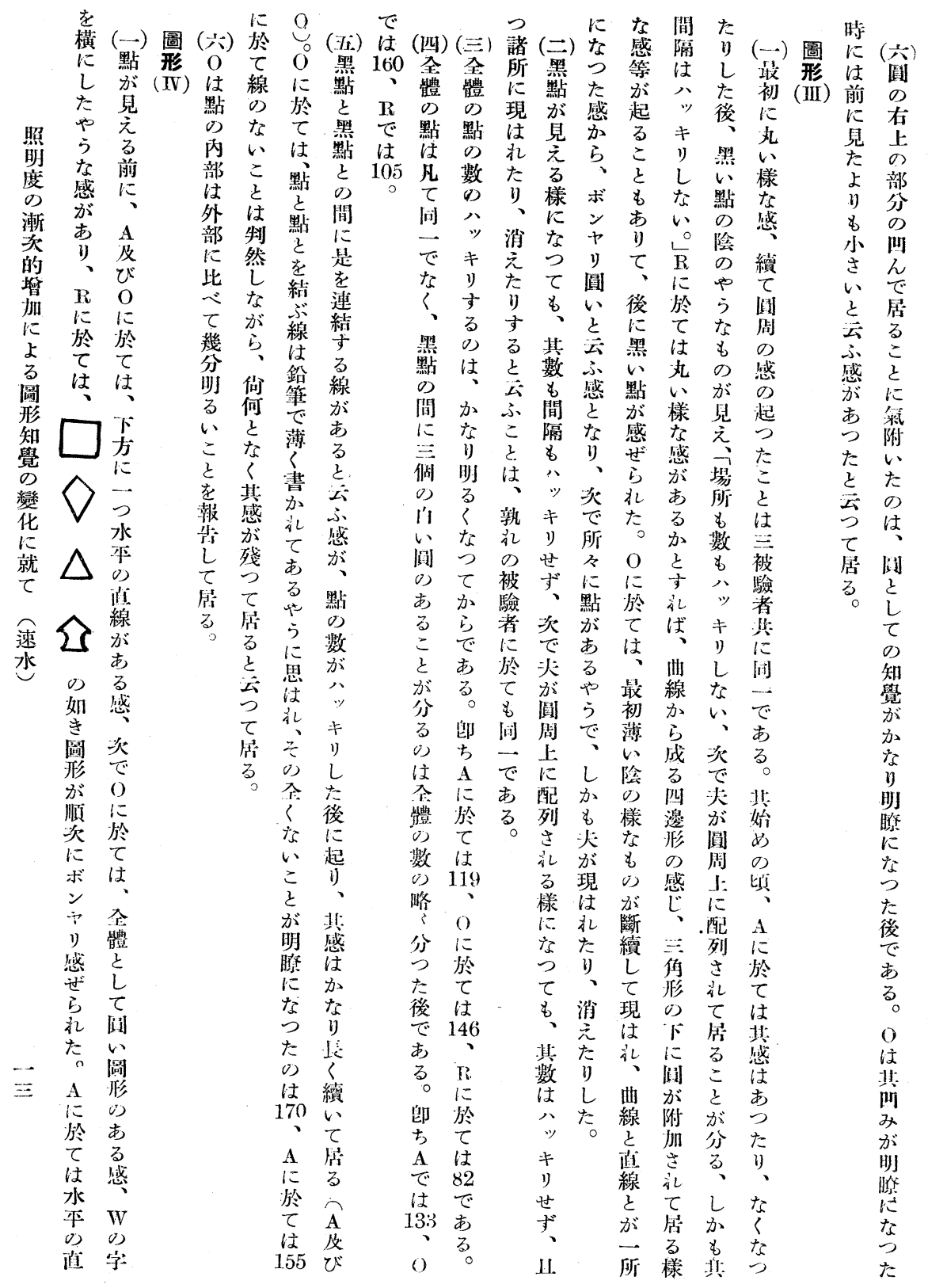




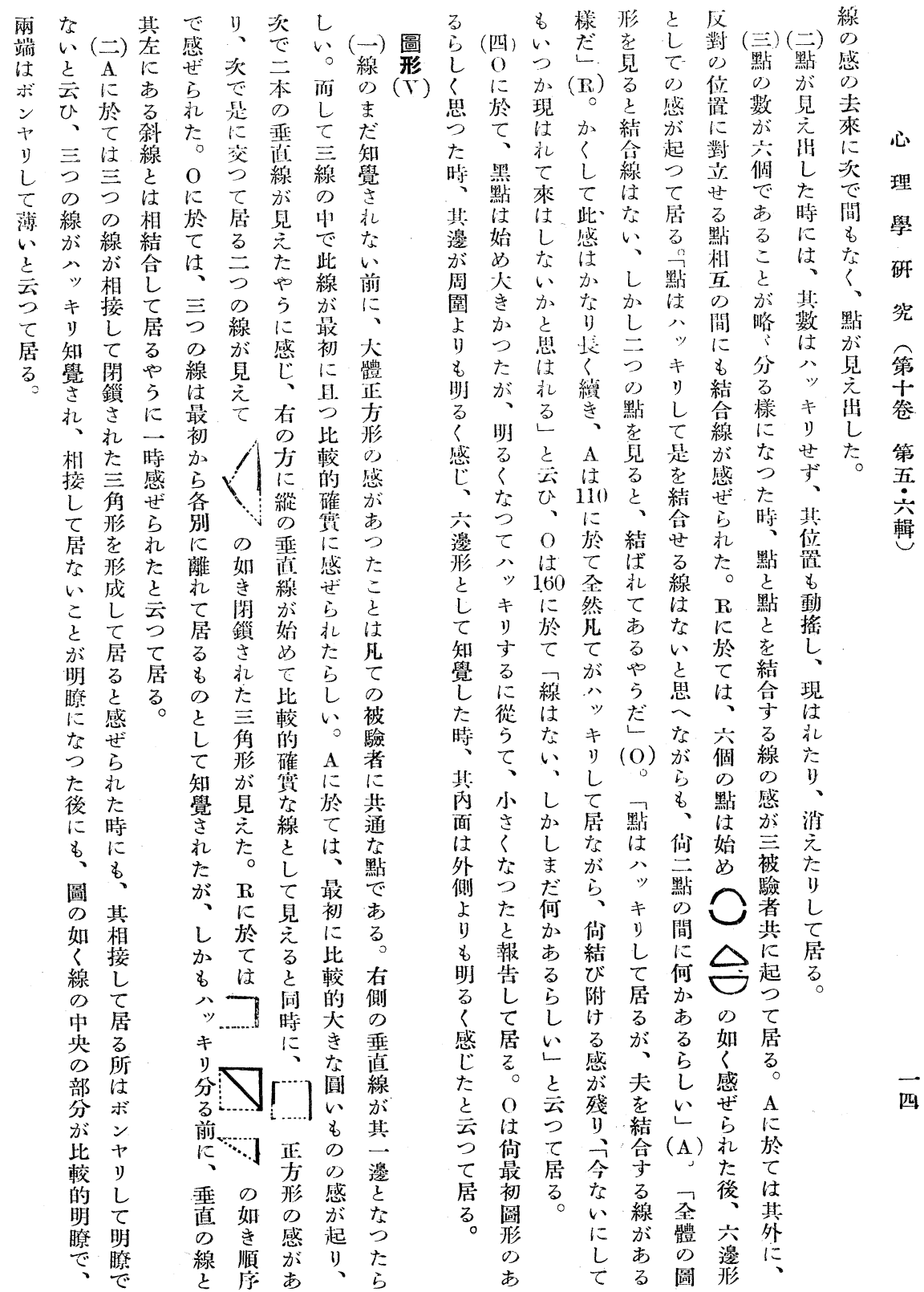




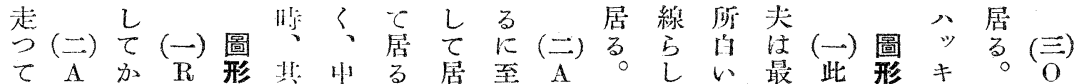

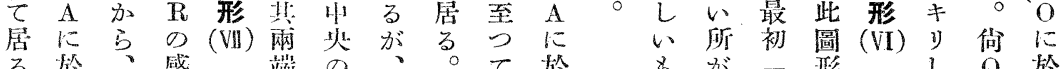

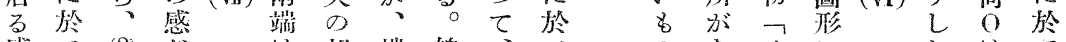

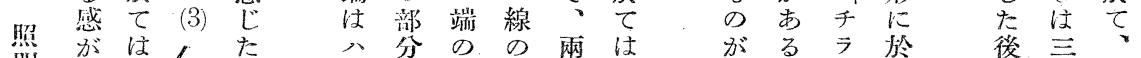

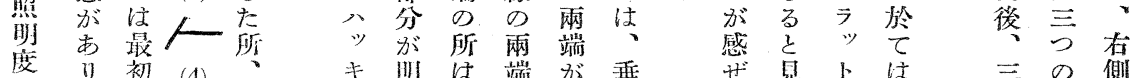

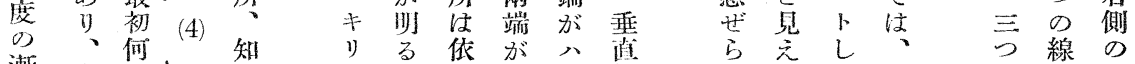

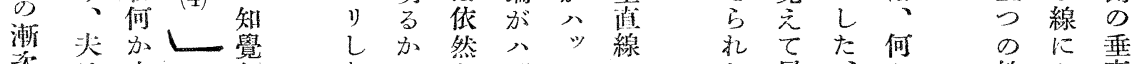

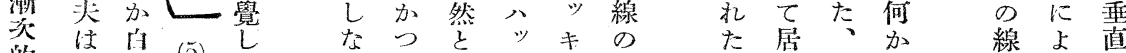

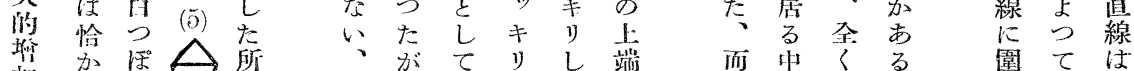

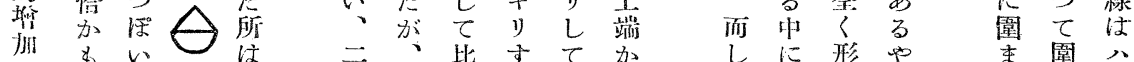

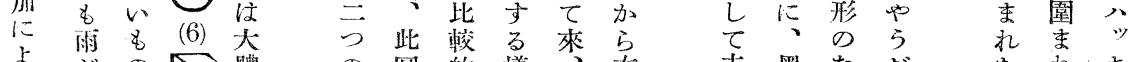

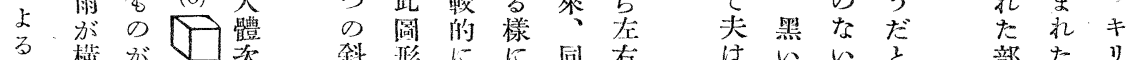

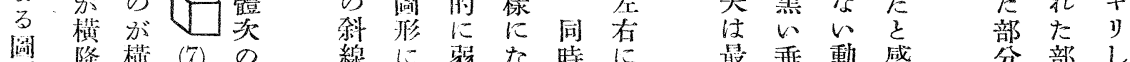
橉降横 (7) の 線に弱な時に最垂動感分部し

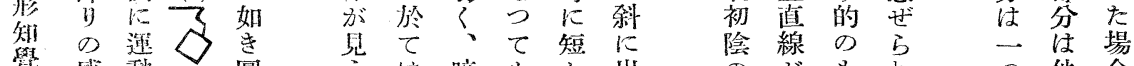

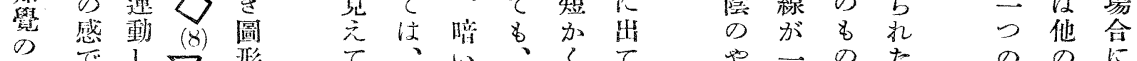

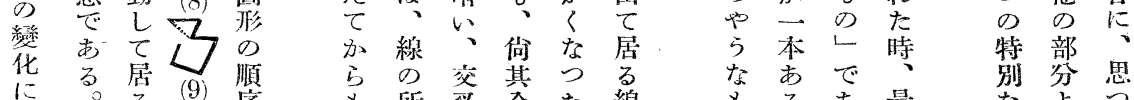

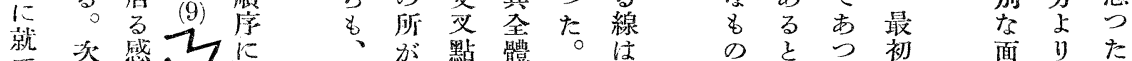

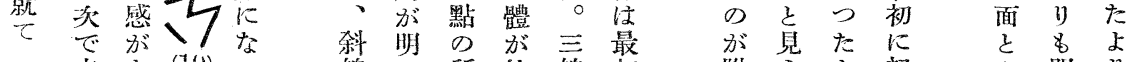

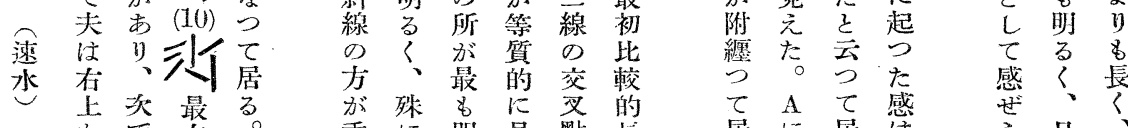

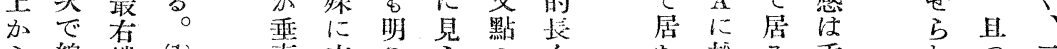

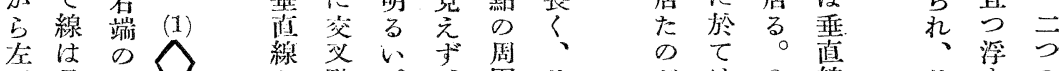

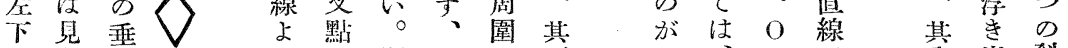

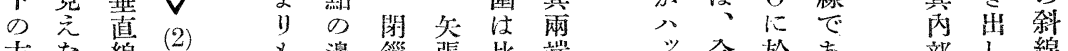

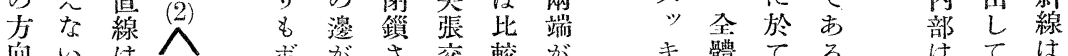

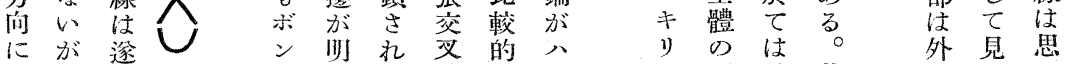

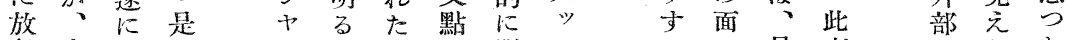

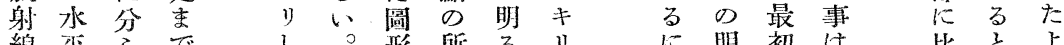

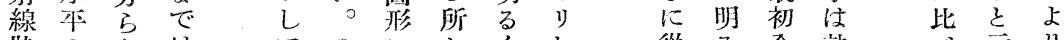

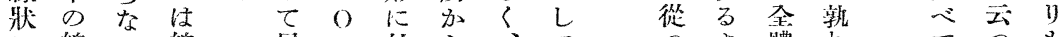

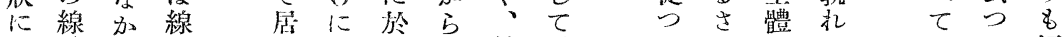
雨がつる然て三線居てでがの明て 短

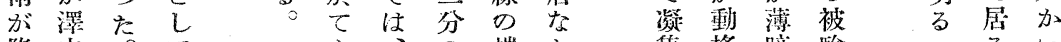
降崩。穴 一 $\tau$ 體感

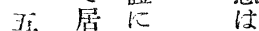

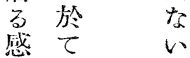
亚的 變行線 た横負

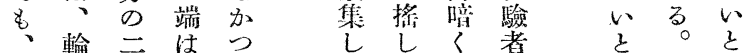

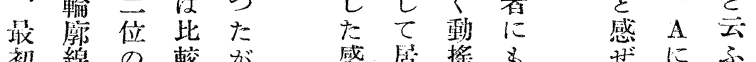

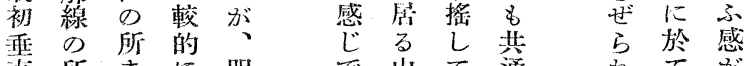

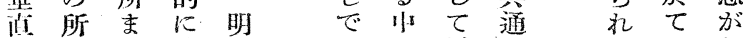
線茂で暗瞭市に居でた。导た

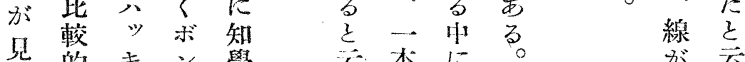
见的 $\neq$ 二覺去本に方去

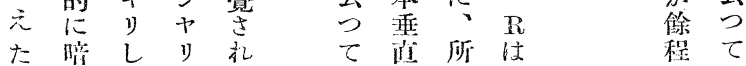
0 出 


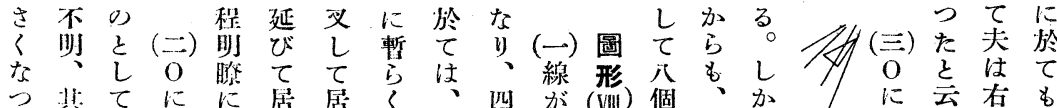

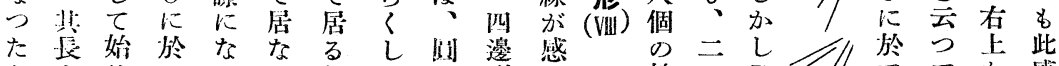

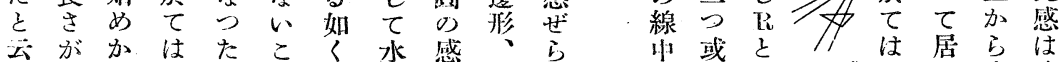

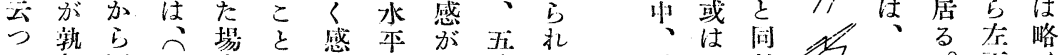
て四

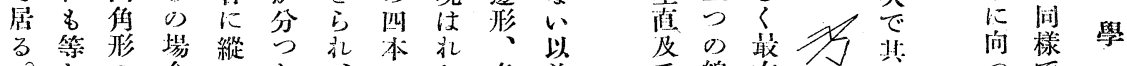
。し の 合のた、のた多前垂線右、势つで

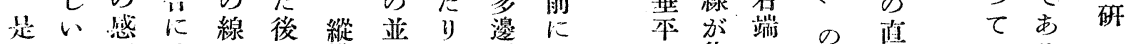

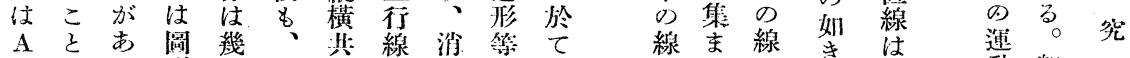

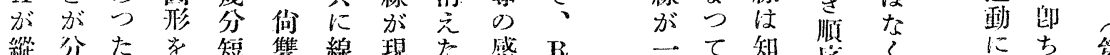

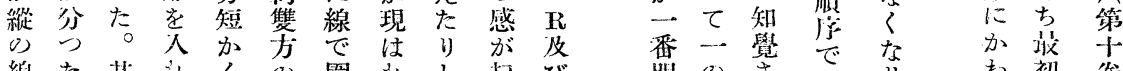

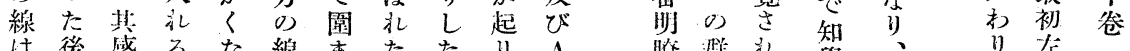

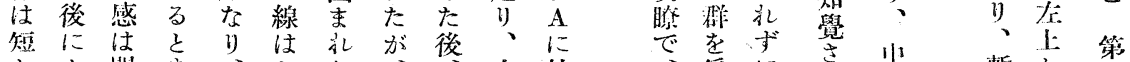

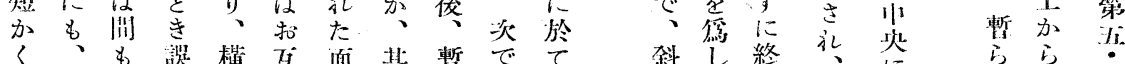

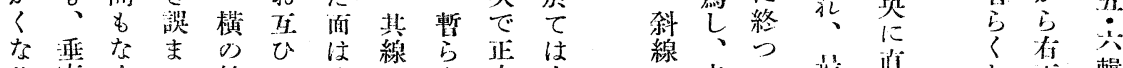

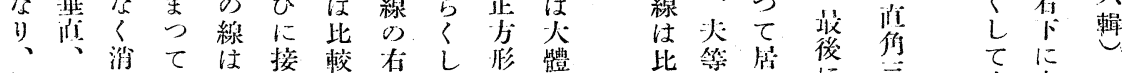

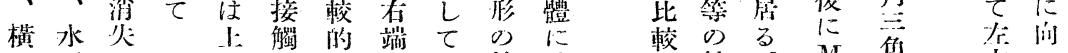

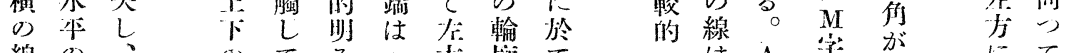

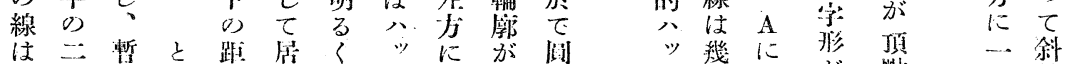

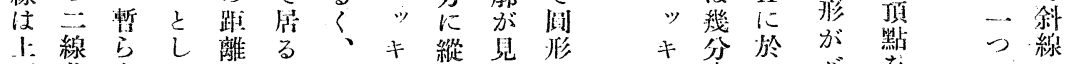

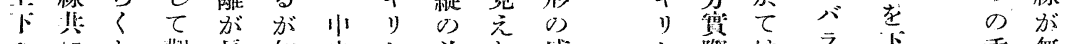

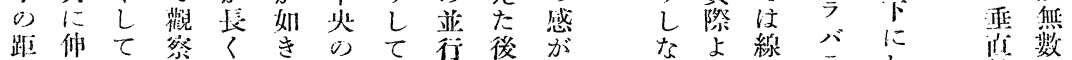

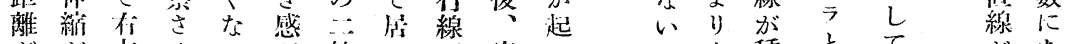

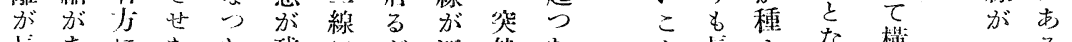

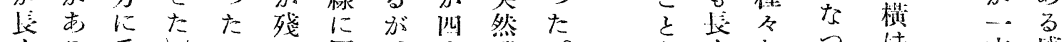

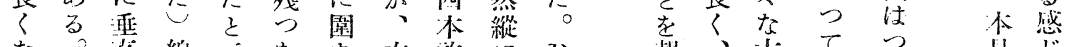

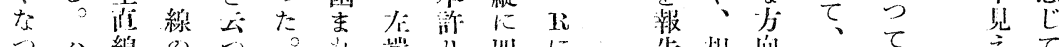

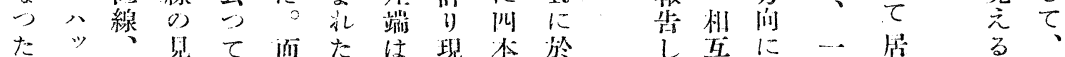

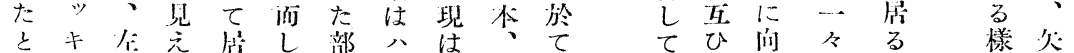

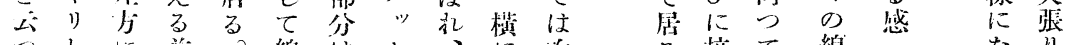

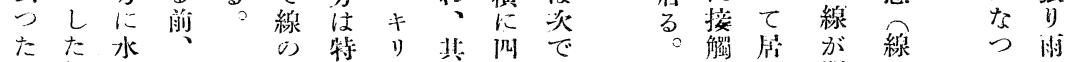

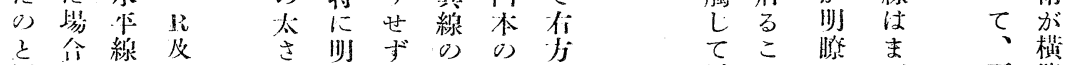

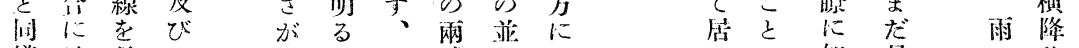

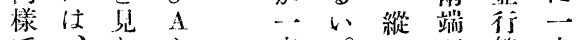

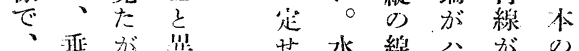

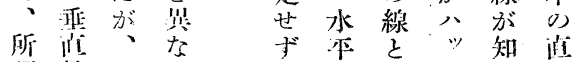

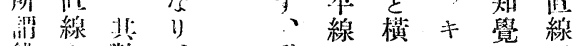

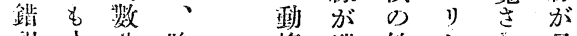
润水及众摇縱線儿和見

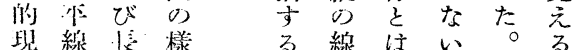

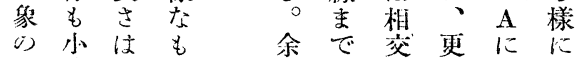

るが知兄市 や知嶨充降の-

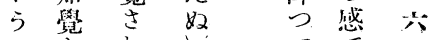
にさ竌的で

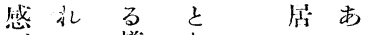
ぜる楾な学感た

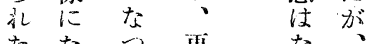
た な

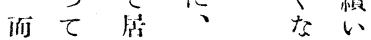




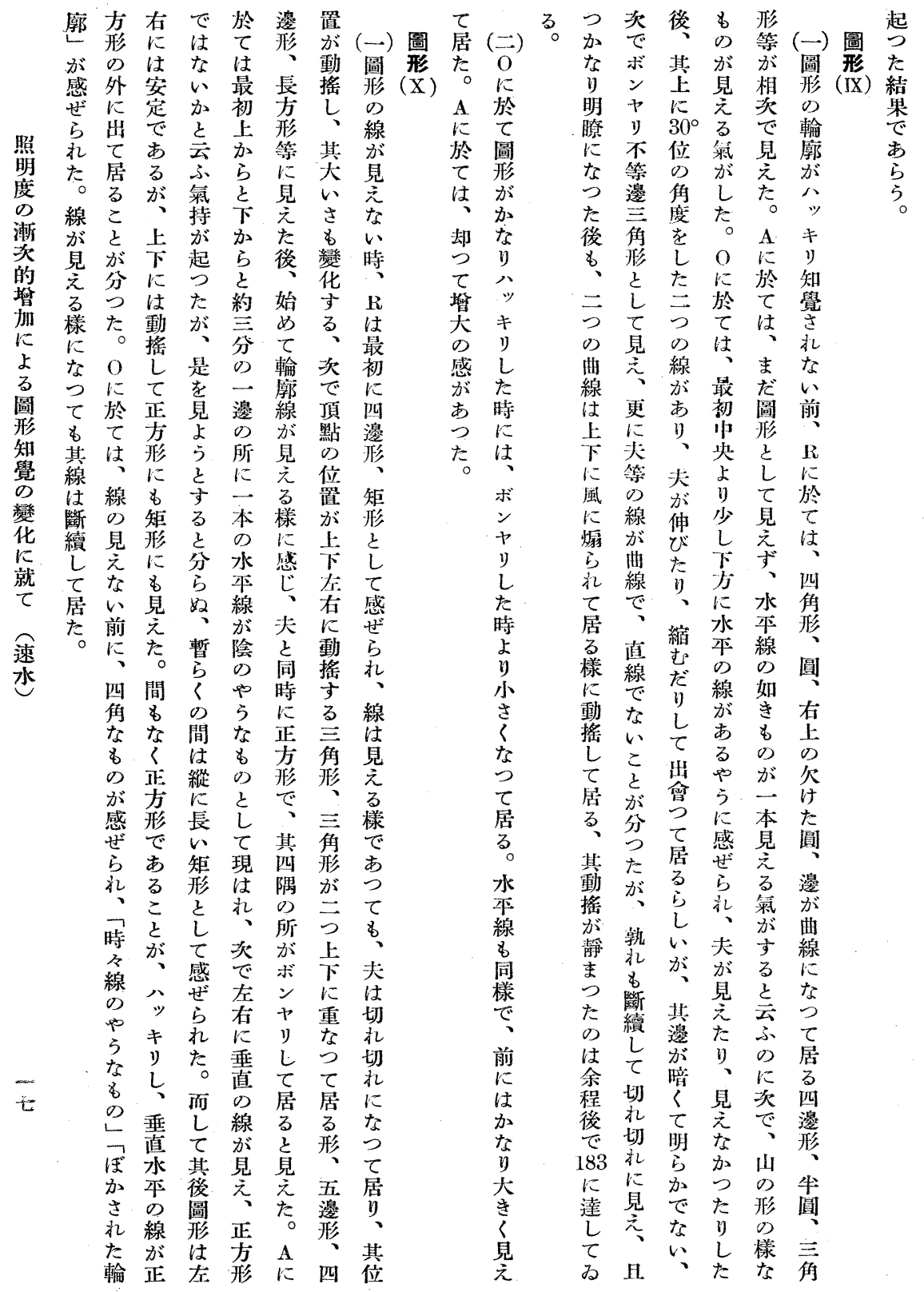




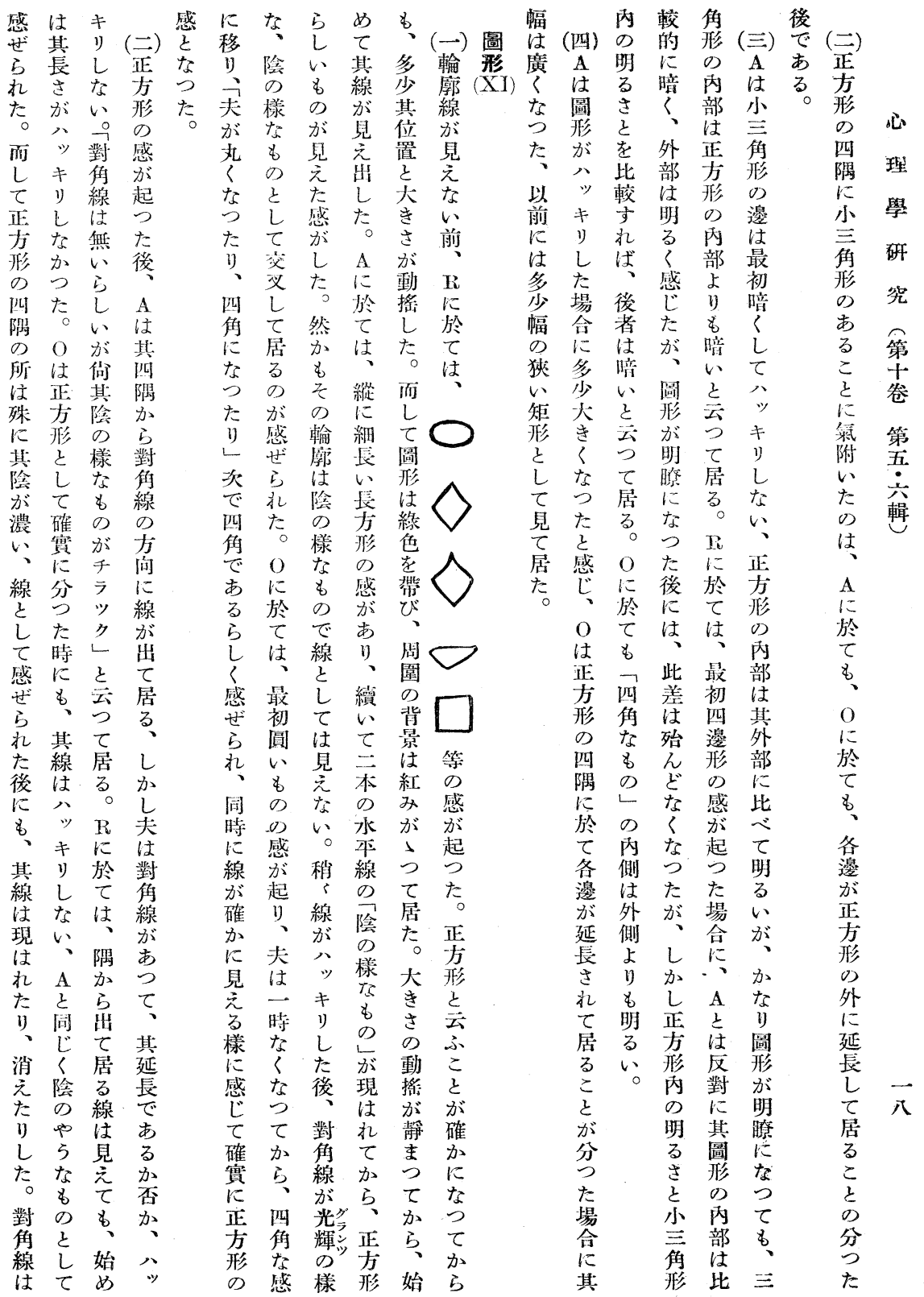




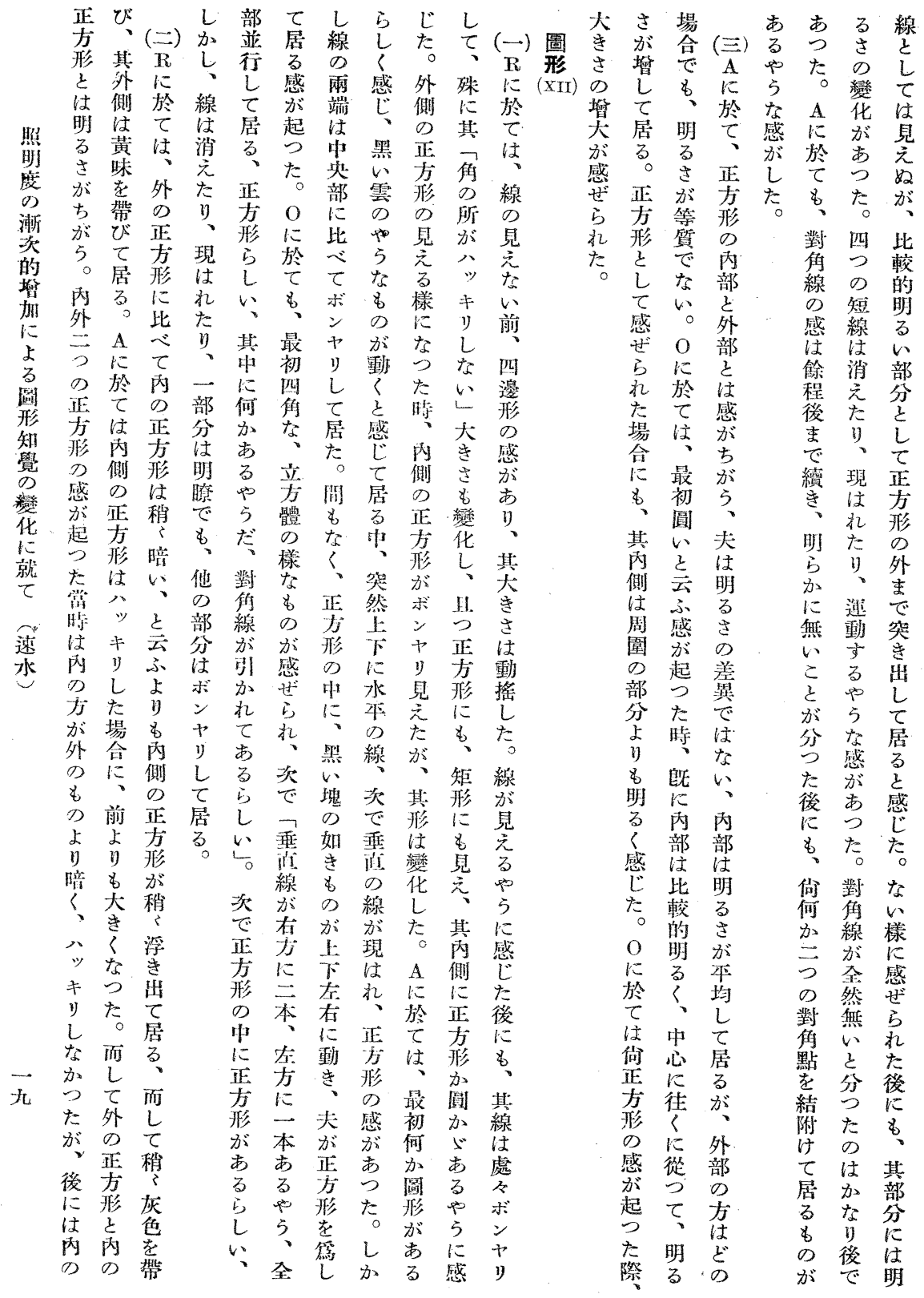




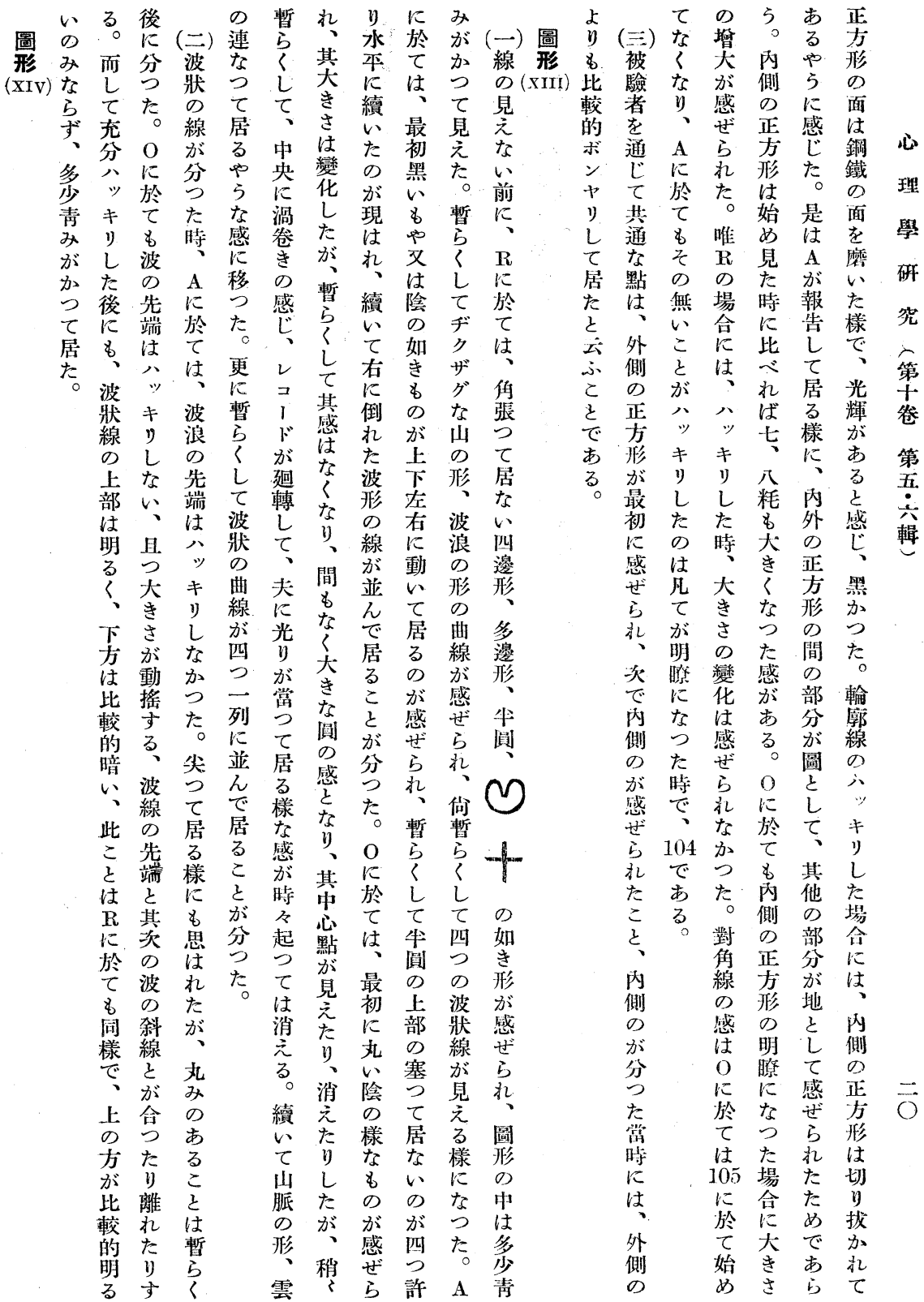




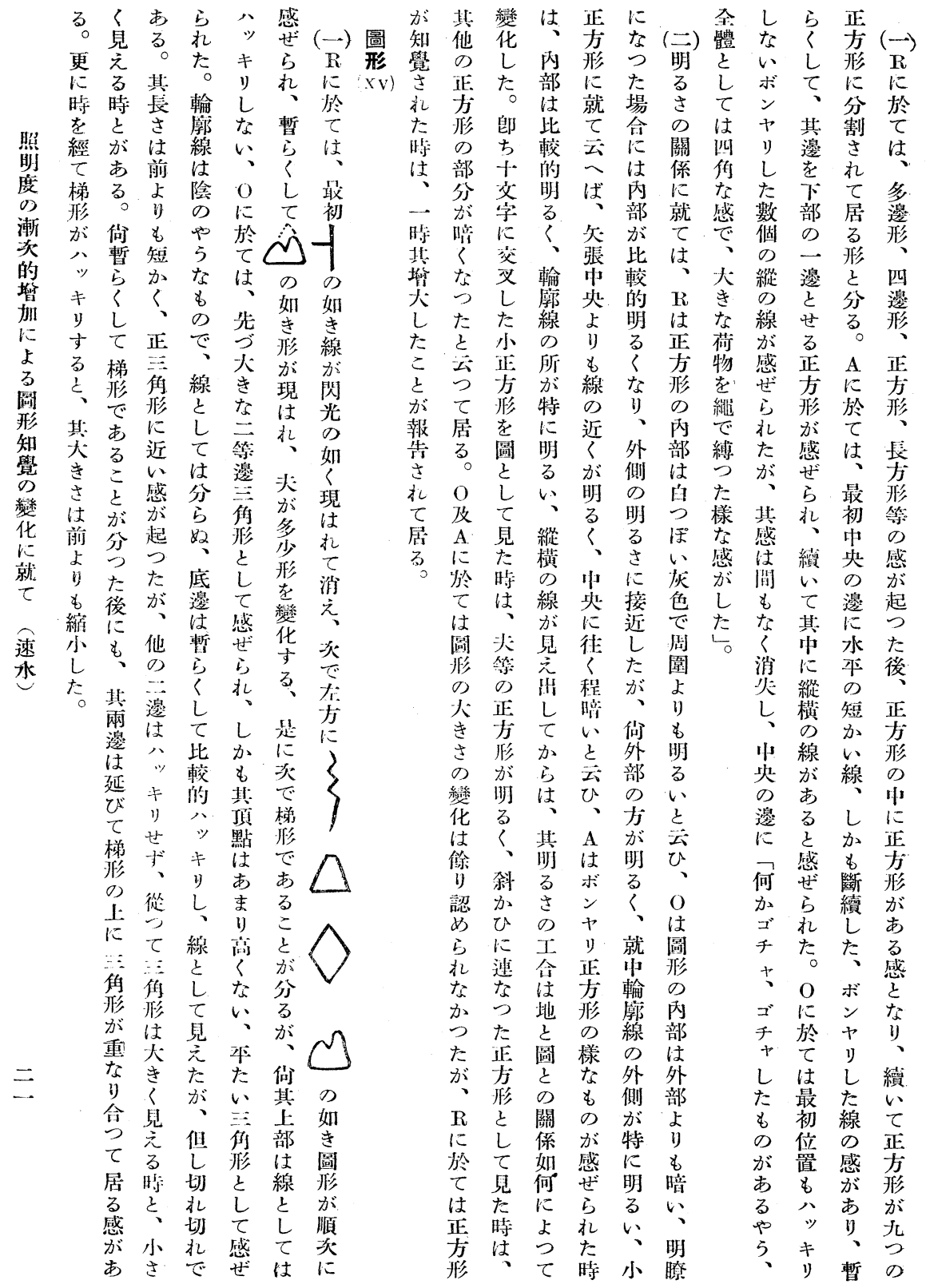




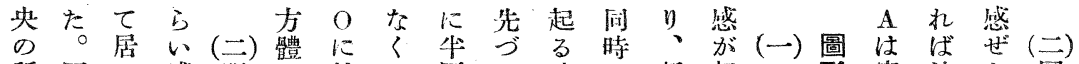
所圖る感明の於 $L$ 圆宍時 $k$ 暫起 $\mathrm{R}$ 形筫波 5 圖

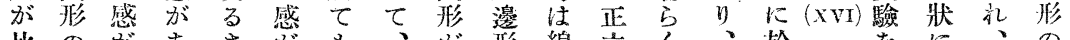

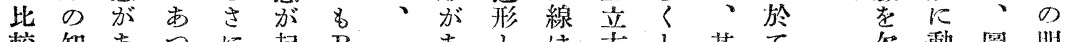

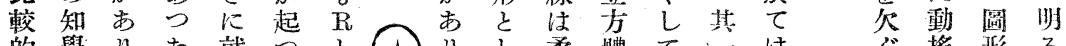

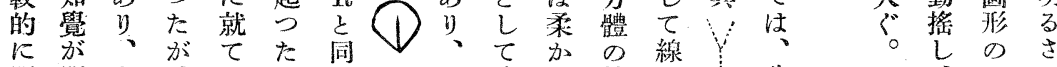

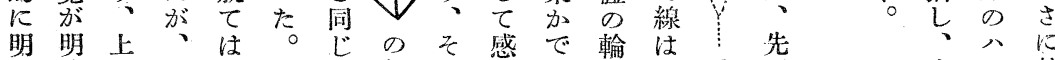

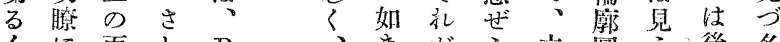

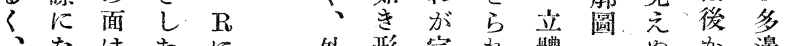

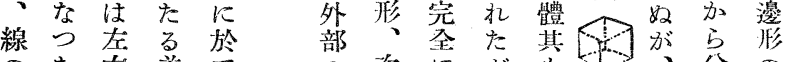

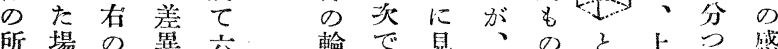

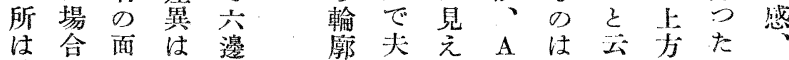
暗、尔形はたに充心にの其

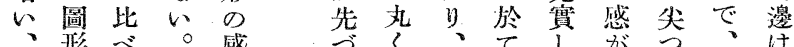

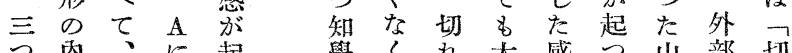

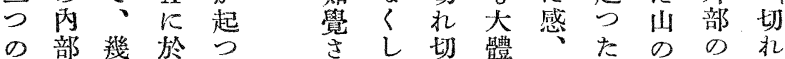

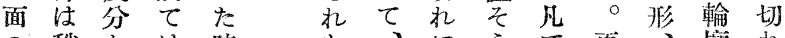

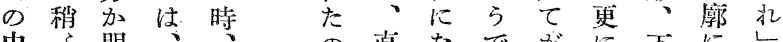

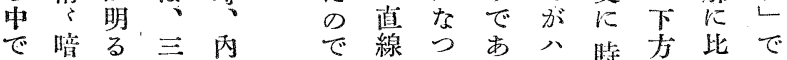

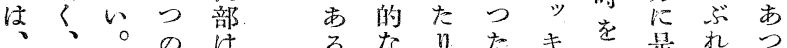

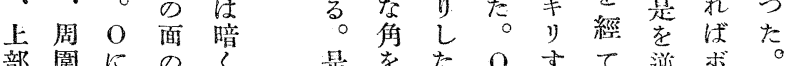
部園に

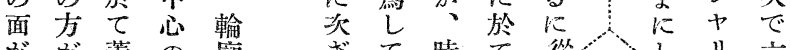
がが菱の廓式て 時て 從いしい六

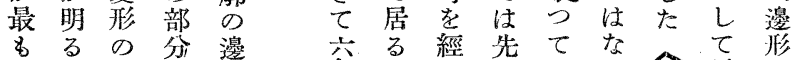

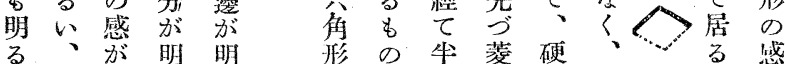

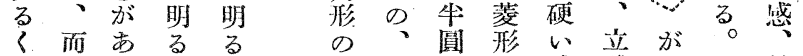
左しつく次宍は感體現A 線 側てた、心角次感を輪はには の輸時線立加形第㤎な竓拀於依

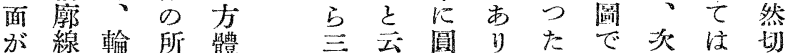
最の廓はの本ふに、。なで先机 \& 所線唶感 の感近左要い左亏゙切

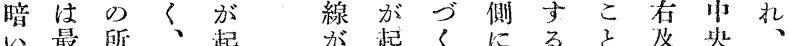

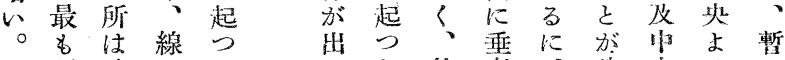

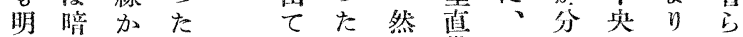

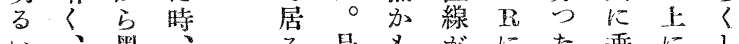

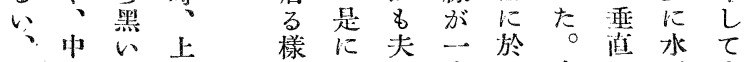
圖央㓌の水上朴立の本立 形部染面感り完現外體線の方 のはにが满て全は部的が線體

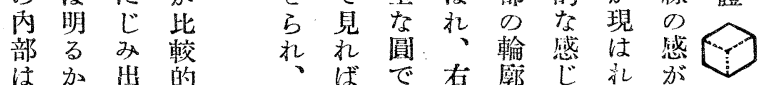

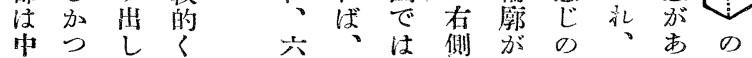

金體キ就 理 と埌は、學 圖後 形には何究 布圖等 書 形報十 いの告 罕 $\tau$ 内。 あ部な第 るはい五 无栐䇂 風に $\mathrm{\text { 輯 }}$ に外に 摇部於 万 $5 \tau$ 辛占 感暗兰 あ $\varepsilon$ 形 つ云公 t $\frac{L}{\tau}$ 動 居 感 摇る。 方蓓整た 著 時 方既

ᄂ る ? 其 艻部三 り の 周 後水圍 ま平上 で線 り 續は名 た \begin{tabular}{cc}
6 & 3 \\
\hline & 5
\end{tabular} 


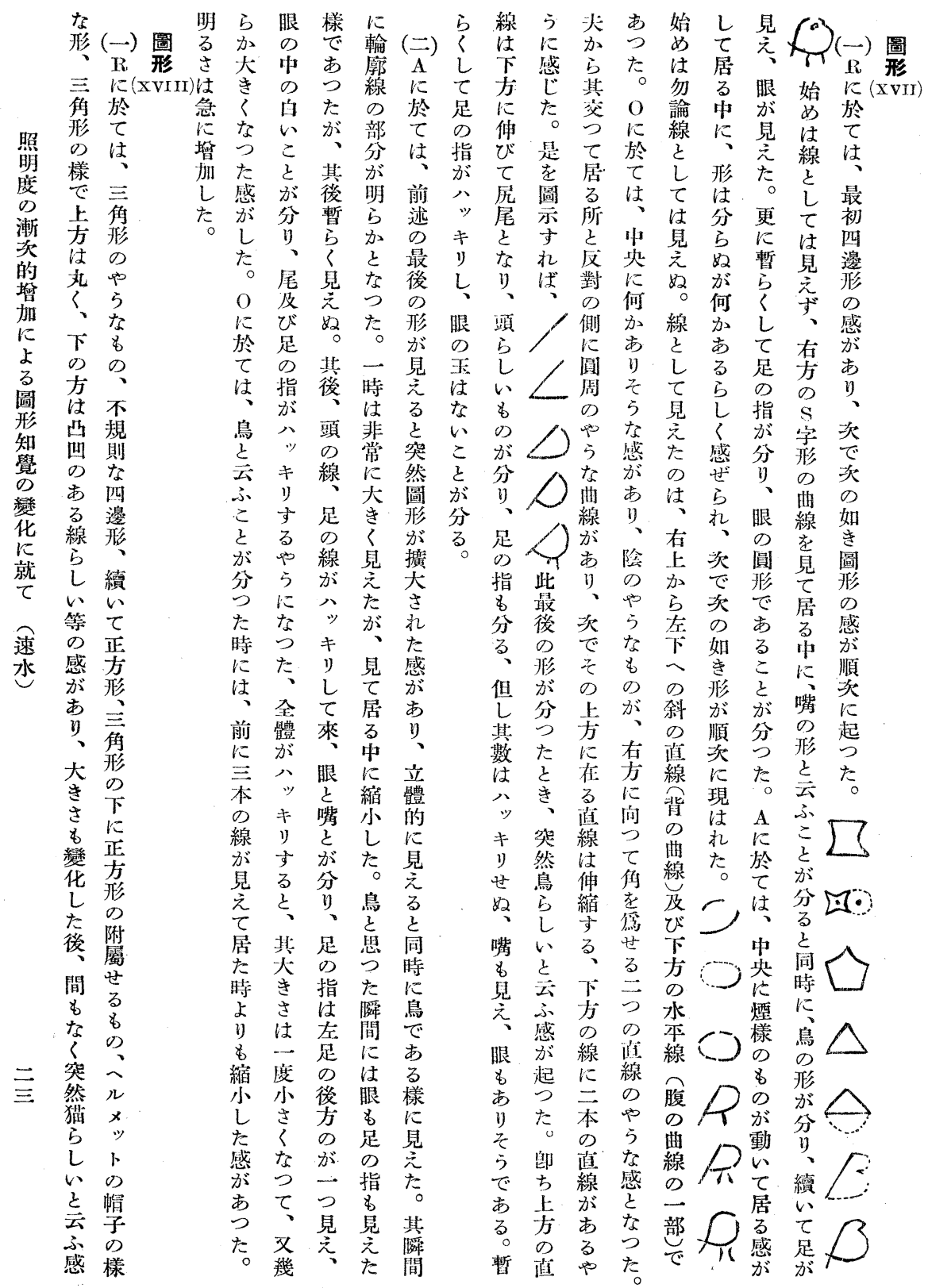




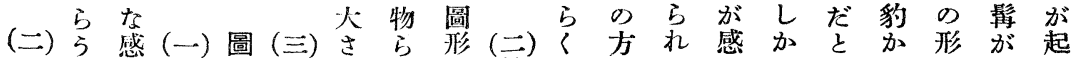

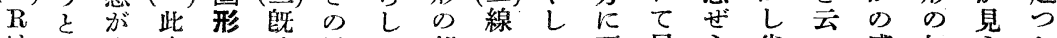

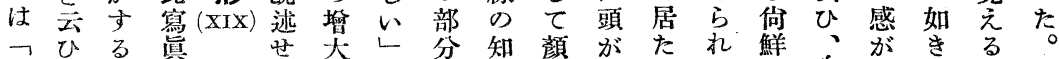

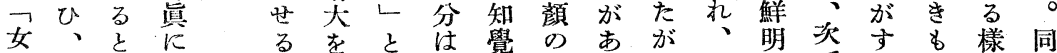

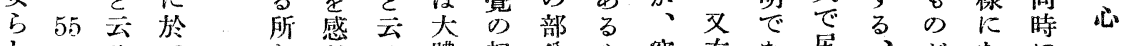
しにひて出ひ體起分や参左な尻、がなに

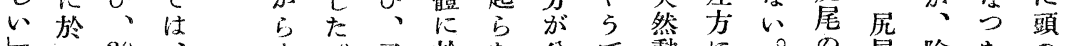

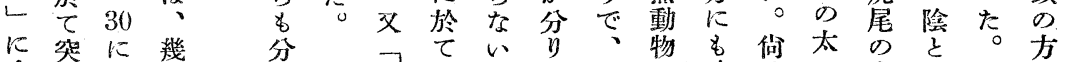
炏然於何当中周前、頭の暗時い方しA

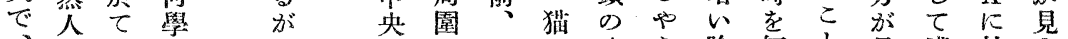

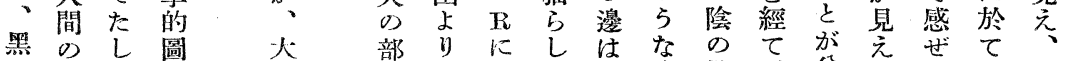

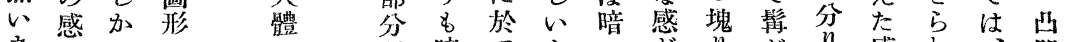

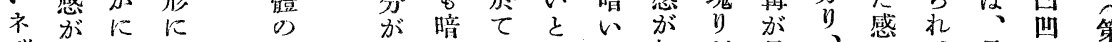

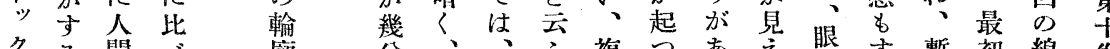

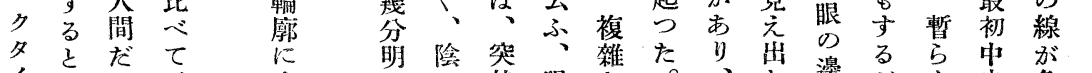

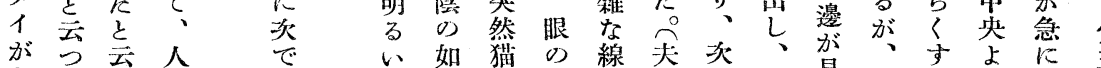

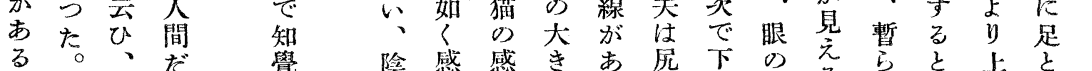

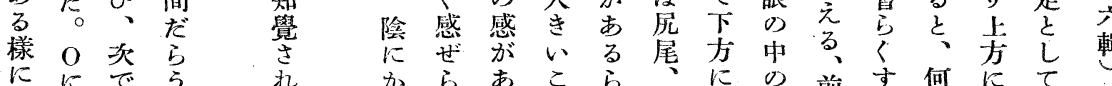

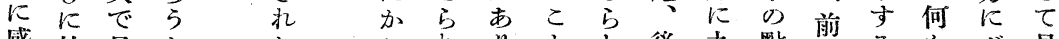

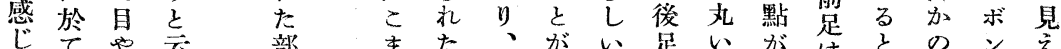

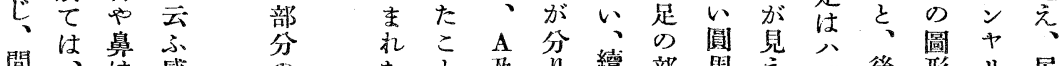

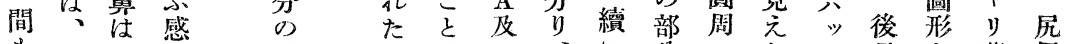

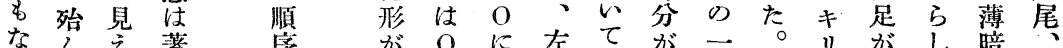

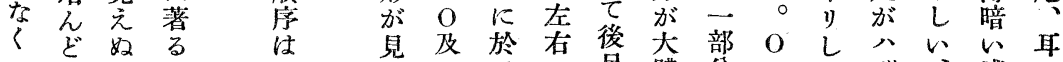

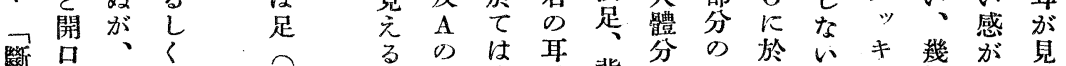

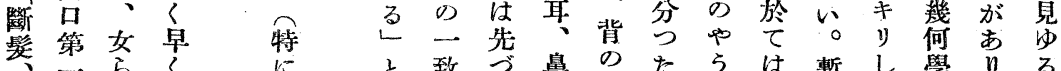

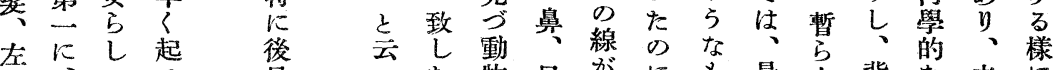

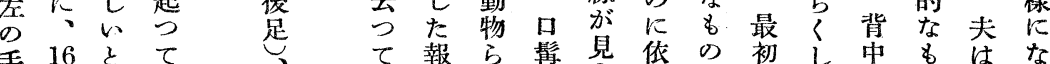

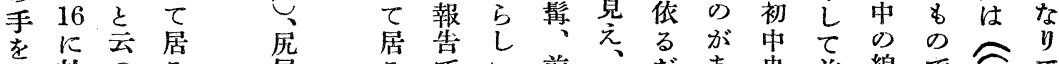

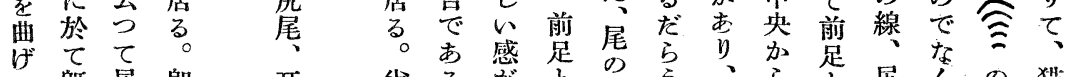

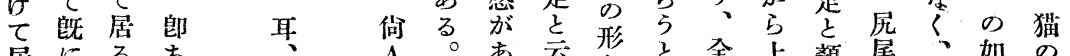

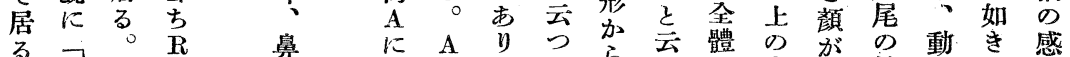

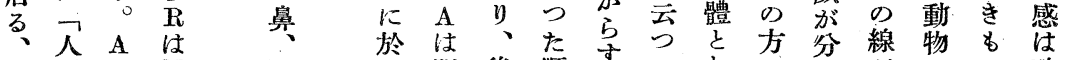

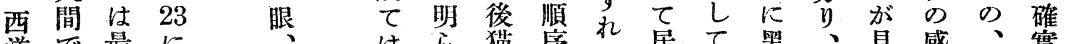

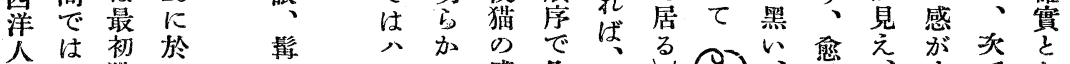

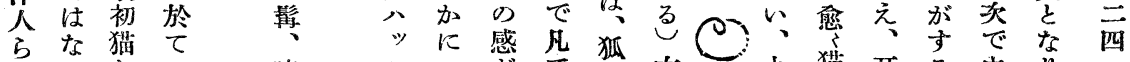

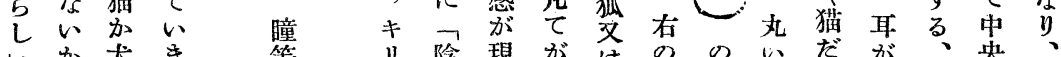

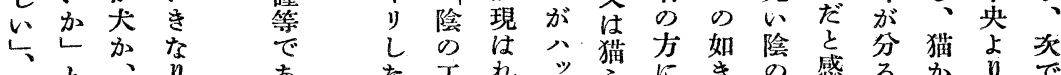

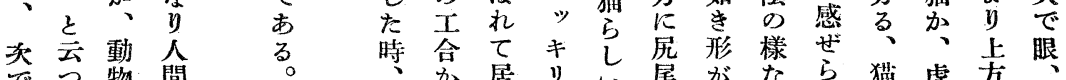

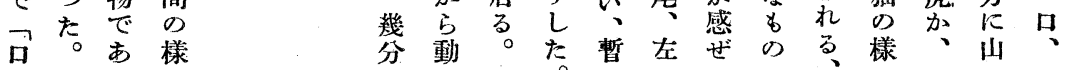
理 學 研 究 策 第 


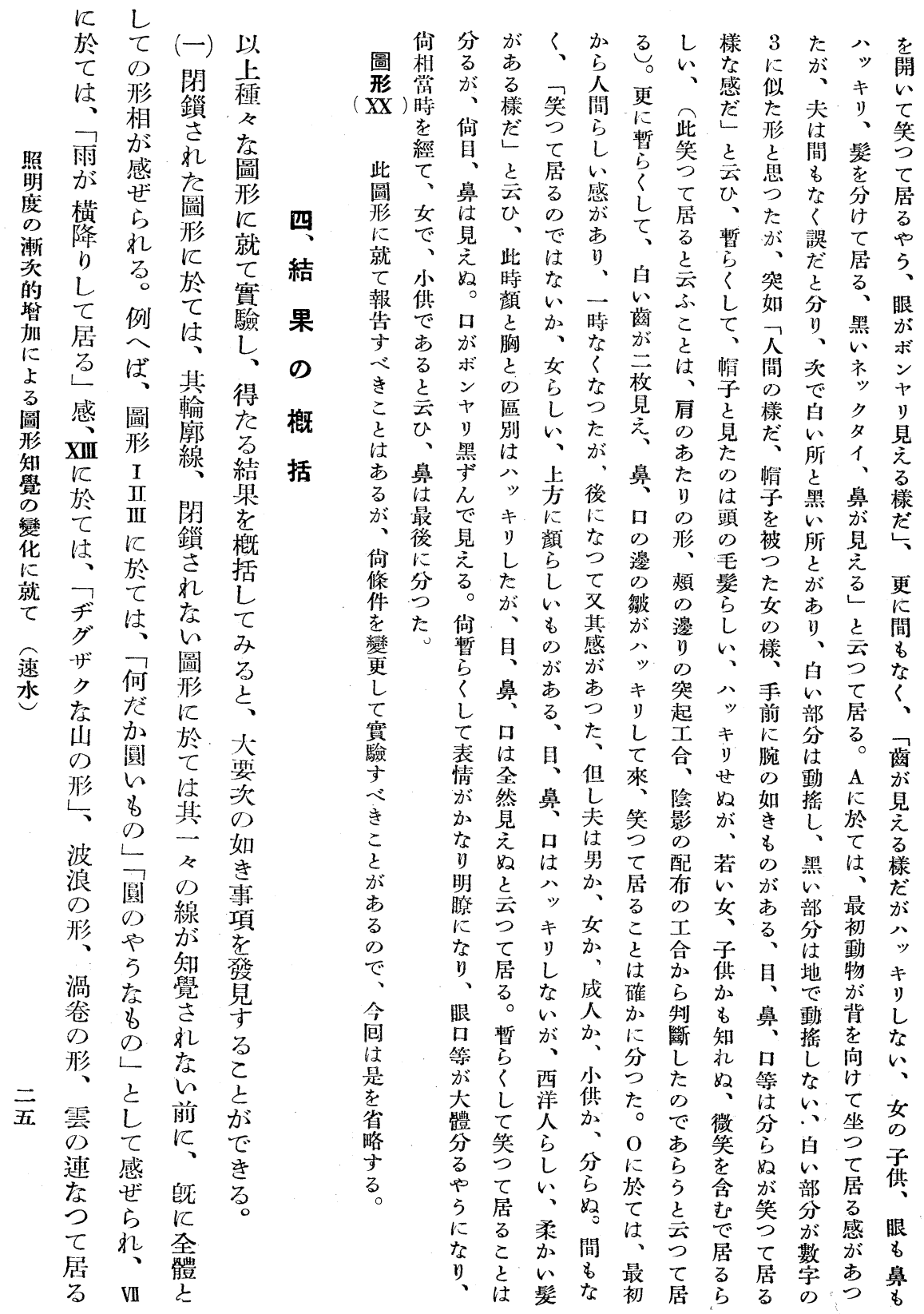




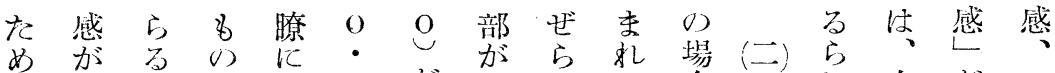

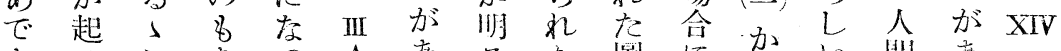

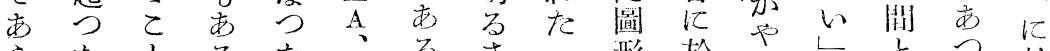

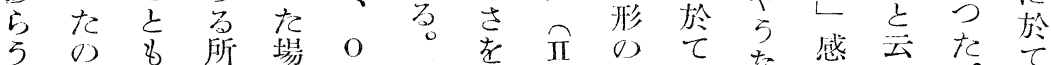

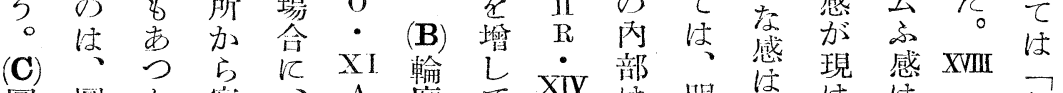

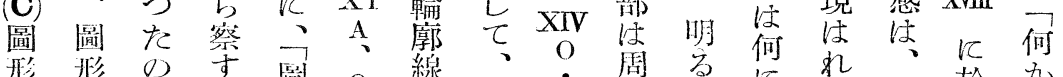

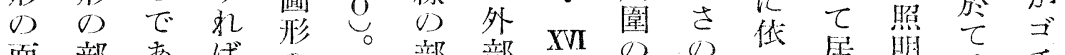
面部 あ 伎可部部 XVI O が分

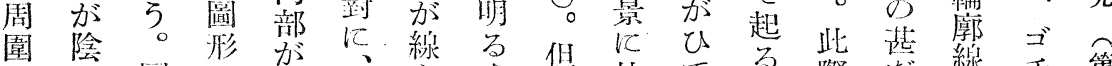

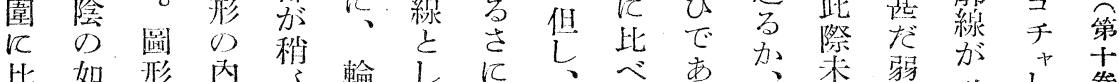

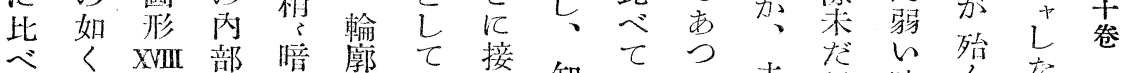

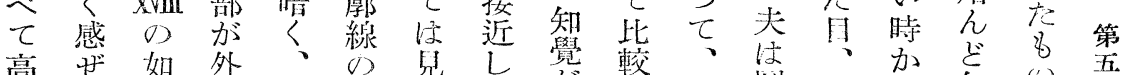

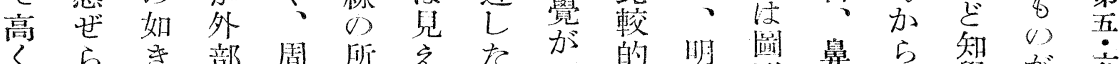

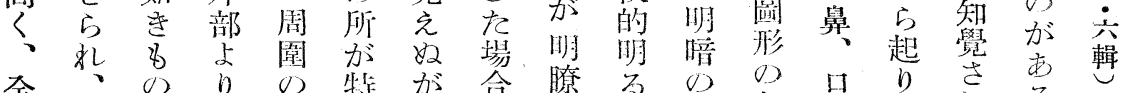

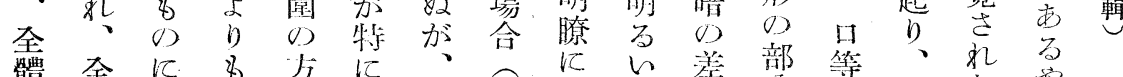
體全に嗾喑 占

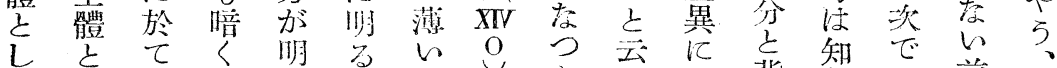
$\tau$ ᄂ

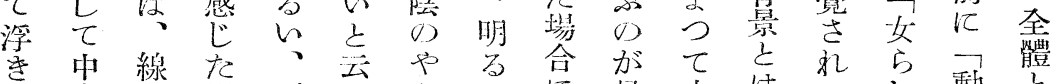

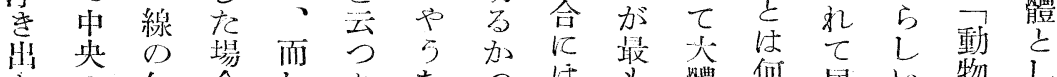

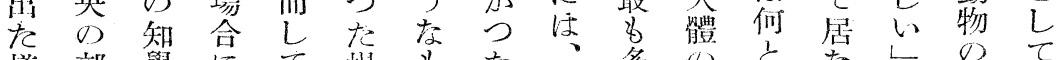

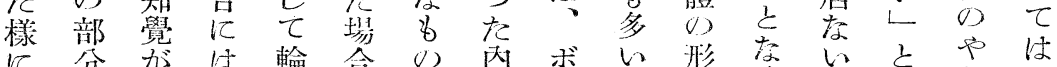

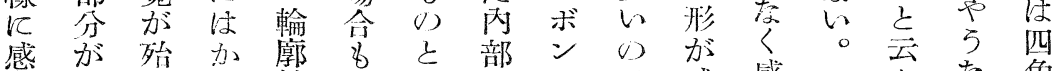

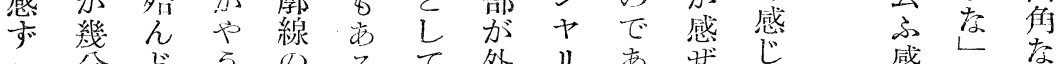
万分

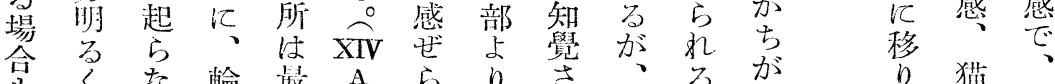
子く存 あ㓌 前線明是た暗た數で吕是感き

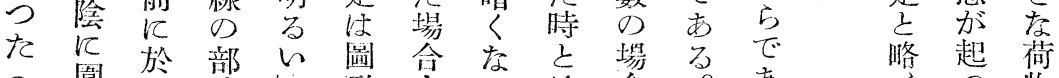
I 圍 於 部

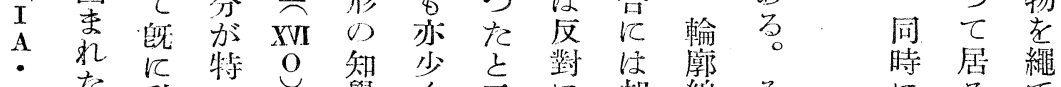
V 形 動 に

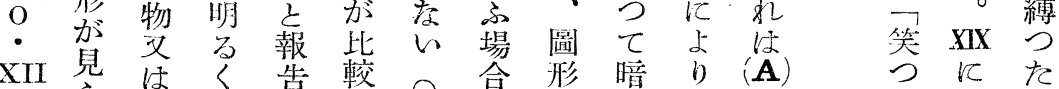

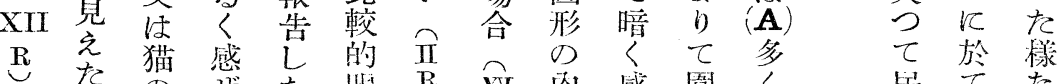

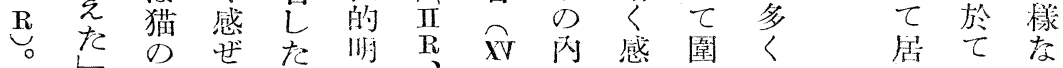




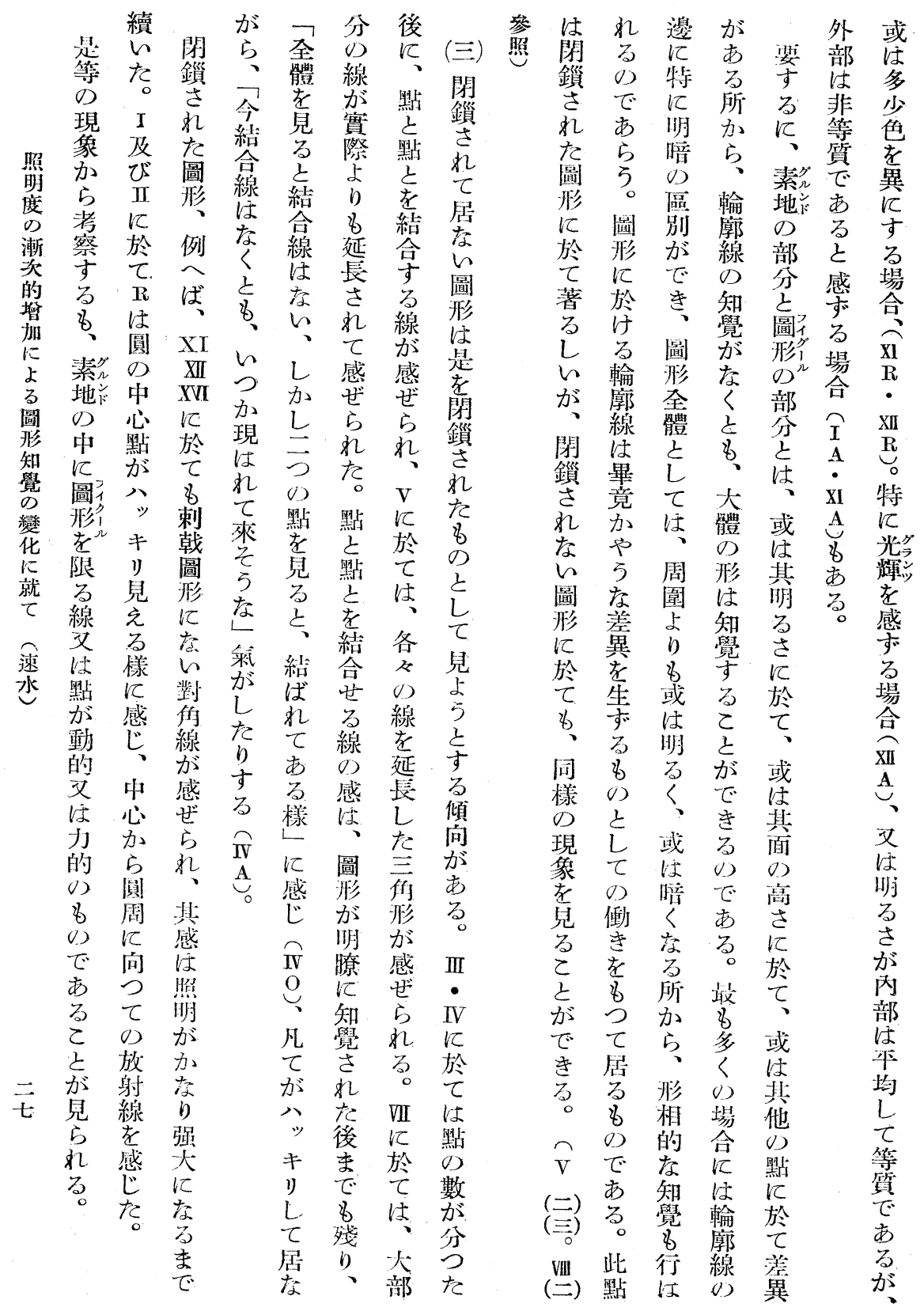




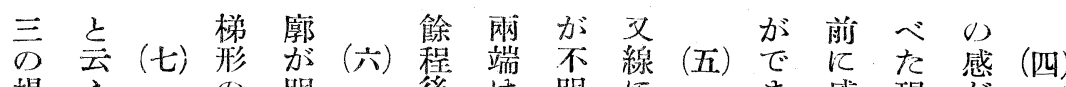

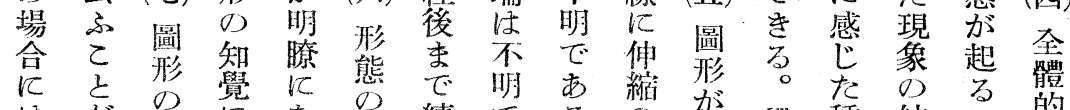

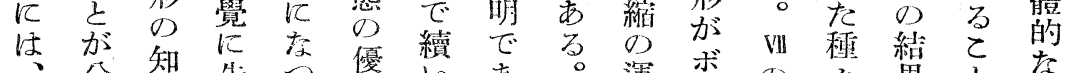

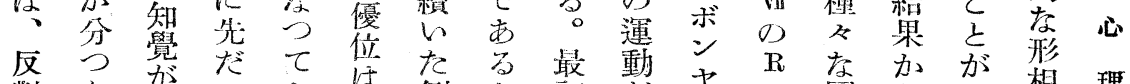

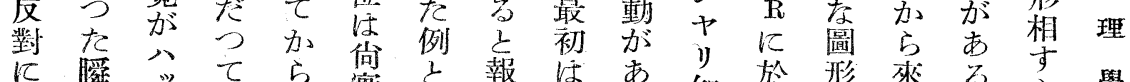

に僢

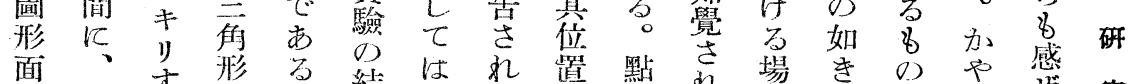

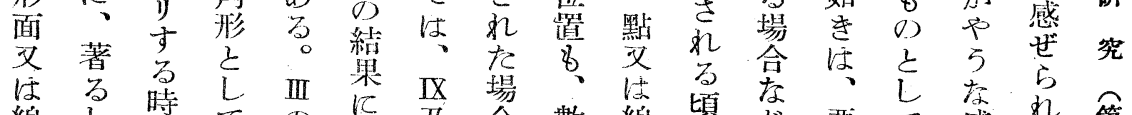

線し 時て

縮 大 急 感 6 白

小き圖热圓明於る

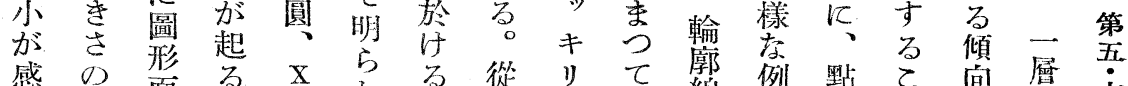

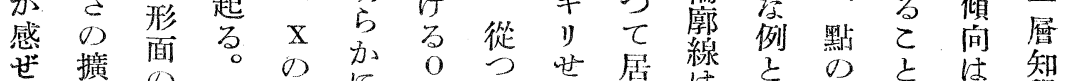

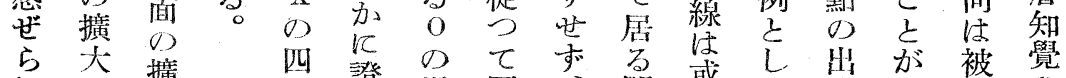

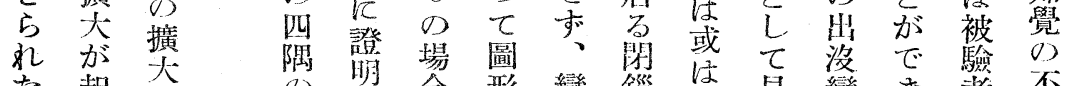

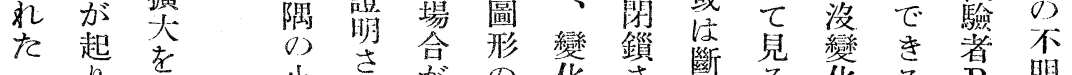

VI 、 感 当热方

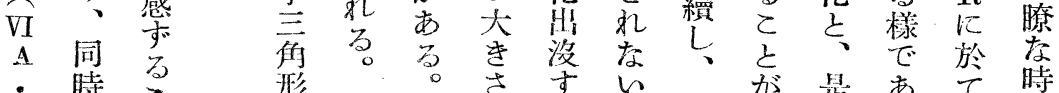

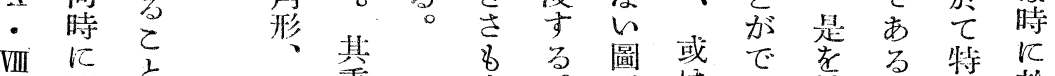

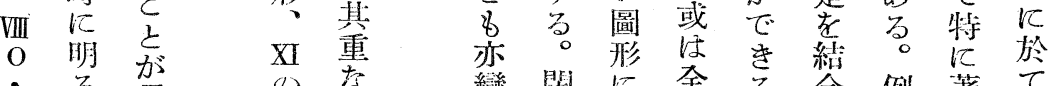

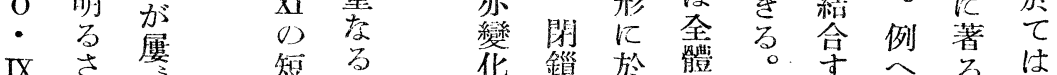

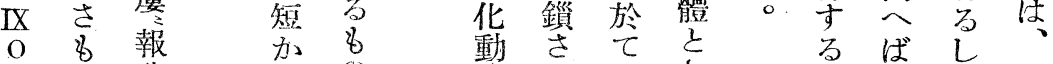

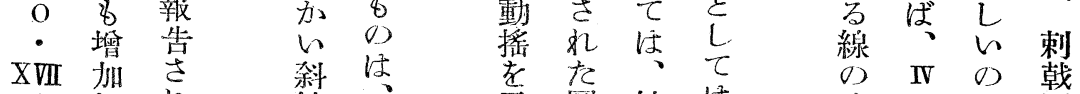

O L 机線 贫圖線は感に艺圖

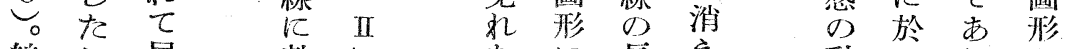

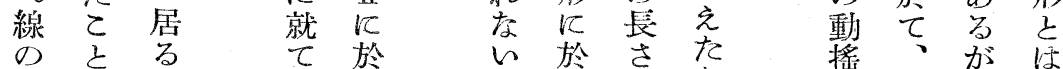

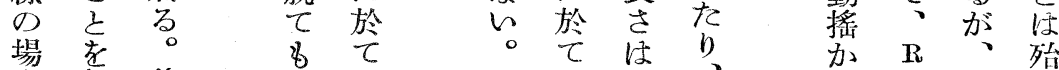

合報殊同圖加\& 制・方是

に告に樣の起點ほ

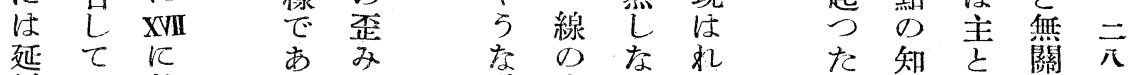

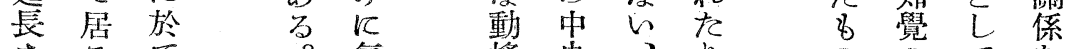

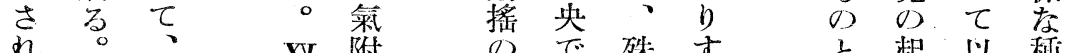

狆 $\mathrm{XV}$ 附 O で殊 す

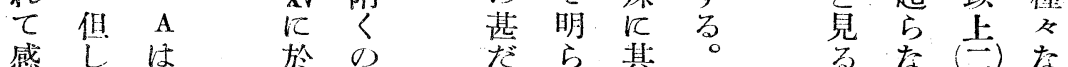

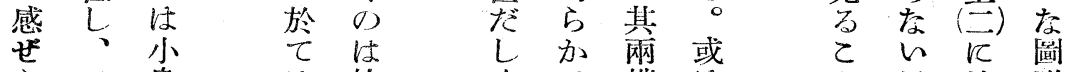

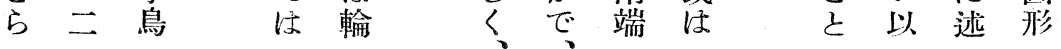




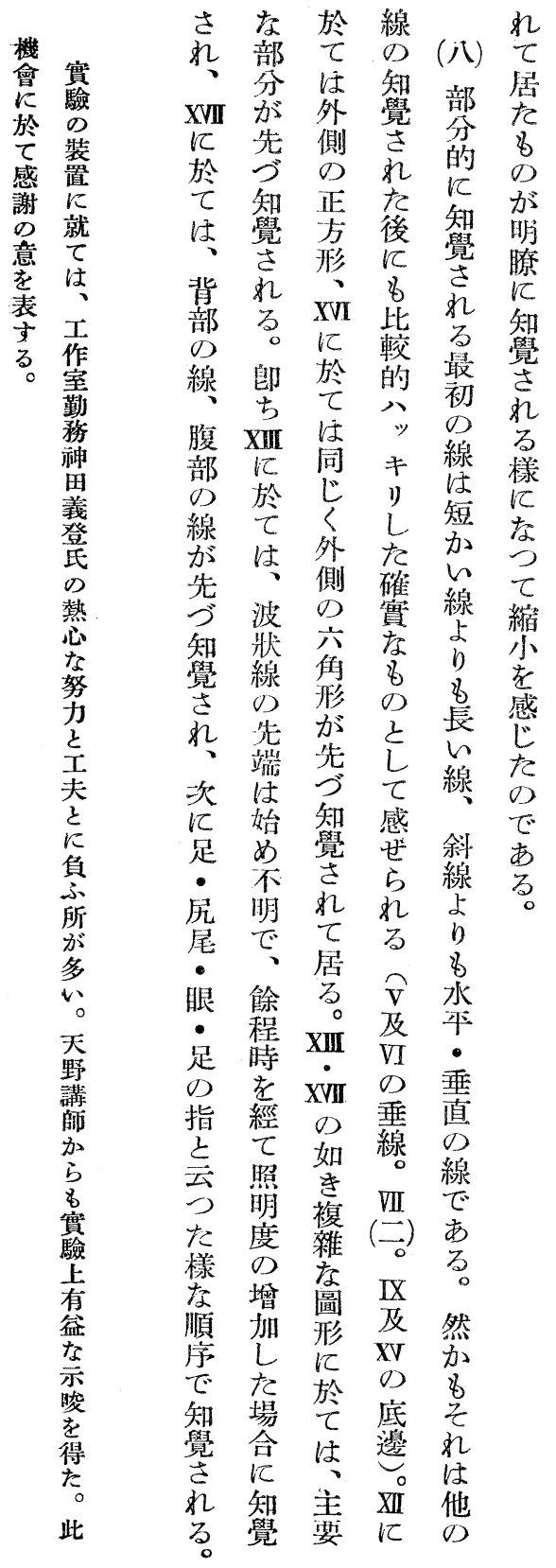




\title{
The Japanese
}

\section{Journal of Psychology}

\author{
(From th:e Psychological Institute, Keijô Imperial Unicersity)
}

\section{The Changes of the Figure Perception under the gradual Increase of the Illumination}

(Abstract)

by

\section{Hirosi Hayami}

Problem: What is the structure of the perception when the external objects are not clearly perceived? What changes undergoes the perception, when the illumination is gradually increased? What is the rôle of the contour lines in the perception? To answer these problems is the object of the present experimental study.

Apparatus and Procedure: Utilizing a Iodge's tachistoscope, figures written on a white paper $126 \times 93 \mathrm{~mm}$. in size are presented in a dark room. The illumination of stimulus figures is performed by means of a 30 watt electric lamp. The gradual increase of illumination (from $1.2 \mathrm{w}$ to about $7.6 \mathrm{w}$ ) is adjusted by a water rheostat placed in an adjoining room. The changes of the perception observed by the subjects who look in at the window of the camera, are reported to the experimenter by means of a telephone. The figures used are 20 in number (ree Fig. 1, 2, 3 in the Japanese text!

Summary of results:

(1) Before the contour lines in closed figures, and the reparate lines in unclosed figures, are not yet perceived, the "physingmomy" of the figures as a whole is felt (by which I mean the previous state of dim perception mentioned in (5)). For example, Fig. I and II are felt as "somehow round" tigures; Fig. VII as " a slanting rain"; Fig. XVIII as "a zigzag shaped mountain," or as "the shape of billows" etc.; Fig. XIV as "square shaped luggage bound with 
ropes." In Fig. XIX "something like a human being" is already recognized when the illumination is quite weak.

(2) This fact seems to be felt by the difference between the figure and the ground. (a) In most cases, the inside of the figure looks brighter than the outside. (b) Sometimes along the contour lines, something like a faint shadow is observed. Sometimes, on the contrary, the vicinity of the lines looks particulary brighter; in which case the inside of the figure seems somewhat darker than the outside. (c) In some cases, the surface of the figure or the part enclosed with the sepatate lines seems to stand in relief. In other cases, they appear tinged with different colours, or different in degree as to the homogeneity of the surface.

(3) In unclosed figures, there is a tendency to perceive them closed, so that almost all lines seem prolonged. In such closed figures as Fig. XI, XII, and XIII, diagonals not existing in reality are felt and the feeling remains until the illumination become considerably intense and the perception clear.

(4) Even when the "physiognomy" of the figures as a whole is not yet felt, various shapes which have no similarities with the stimulus figures occur especially in the case of the subject $R$. The reason reems to be due to the phenomena mentioned in (3).

(5) When the figures are dimly perceived, the contour lines are broken, and appear and disappear. Sometimes the movement of their expansion and contraction is reported. In the unclosed figures consisting of groups of lines or dots, the length of the lines is uncertain, their positions and numbers, obscure and especially the extremities indistinct. They appear and disappear at times so that their size fluctuates.

(6) The primacy of Gestalt can be proved by the results of this experiment. The chief of them are: (a) In Fig. II, the distortion of the circle is perceived after the clear perception of the contour. (b) As to the white small circles in Fig. III, the small triangles at the corners of the square in Fig. $\mathrm{X}$, and the short oblique lines in Fig. XI, the results are the same.

(7) The sudden expaniion of the surface of figures is often observed, when the perception of the figures become clear. In a few cares, un the contrary, the contraction, especially of lines occurs.

(8) The longer lines are generally perceived earlier than the shorter ones; the perpendicular or the horizontal than the oblique. Those lines perceived arrier are elearer than those perceived later. The mutside square in Fig. 
XII and the outside hexagon in Fig. XVI are perceived earlier. In such complex figures as Fig. XIII and XVII the principal lines are perceived first of all, and the details later. 